SF 427 . $\mathrm{H} 65$

Copy 1 


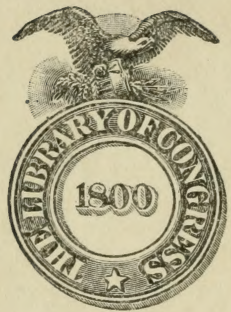

Class SF 427

Book. H65

Copyright $\mathrm{N}^{\circ}$.

COPXRIGHT DEPOSKT. 


THE FARMER'S DOG 


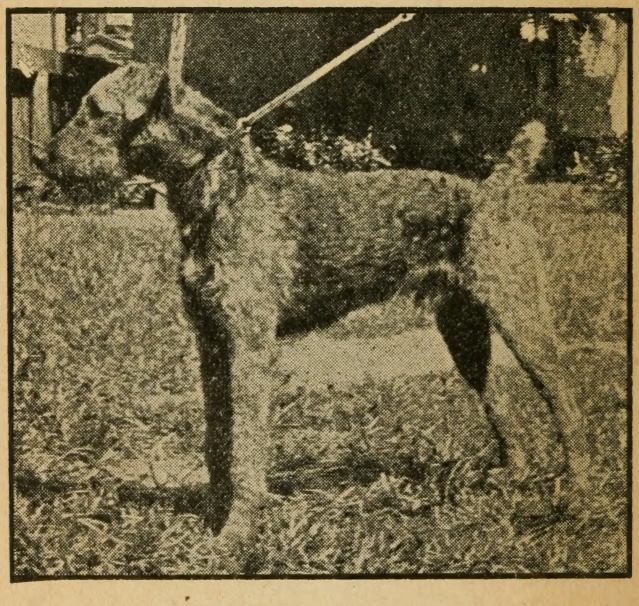

TEDDY THE TERROR.

A Perfect Type of Working Airedale. 


\section{The Farmer's Dog}

\section{FOR WORK, FOR PROFIT AND FOR SPORT}

\section{Albet $\neq B Y$ \\ A. F. HOCHWALT}

\section{AUTHOR OF}

"Dogcraft," "The Pointer and the Setter in America,"

"The Modern Pointer," "The Modern Setter," "The Airedale for Work and Show," "Practical Dog Keeping for the Amateur," "The Working Dog and His Education," "Dogs

as Home Companions," Etc.

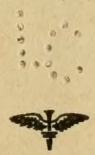

1922

SPORTSMEN'S DIGESI

CINCINNATI 


$$
\begin{aligned}
& \text { SF } 421 \\
& .465
\end{aligned}
$$

Copyright, 1922, Sportsman's Digest All Rights Reserved

AllG 101922 


\section{CONTENTS}

Preface...$\ldots \ldots \ldots \ldots \ldots \ldots$ xir Introduction $\ldots \ldots \ldots \ldots \ldots \ldots \ldots \ldots \ldots$

\section{PART ONE. \\ Useful Breeds \\ Chapter I.}

The Airedale-Short Story-His Possibilities as a Stock and WatchDog As an All-round Sporting Dog.....

Chapter II.

The Collie-The Old English Sheep Dog-Mixed Shepherd Breeds-The Shepherd, or Police Dog......... 15

Chapter iII.

Other Useful and Profitable BreedsBird Dogs and Hounds.......... 31

\section{PART TWO.}

Breeding, Care and Marketing Chapter I.

Breeding Dogs For Pleasure and Profit - General Hints - Importance of Pedigree and the knowledge of what it Represents ................. 45 
Chapter II.

The Stud Dog and the Brood Matron -Oestrum-When it Occurs-Time for Breeding--Care of Matron During Period of Gestation-Parturition 59

Chapter iII.

Care after Whelping-Care of The

Puppies During first Few Weeks -Docking Tails - VermifugesWeaning $\ldots \ldots \ldots \ldots \ldots \ldots \ldots, \quad 74$

Chapter IV.

Selection of Puppies-Value of Bitches to Preserve Strain-How to Market-Conditions of Sale How to Ship $\ldots \ldots \ldots \ldots \ldots \ldots \ldots .61$

\section{PART THREE.}

Training for Practical Purposes

Chapter I.

Early Training Lessons for all Breeds 93

Chapter II.

The Training of the Stock Dog For

General Use on the Farm........ 107

Chapter iII.

Training of the Stock Dog-Continued 121 


\section{PREFACE}

NOT long ago I met a bright young man over in Illinois who had been admitted to the bar about two years before. He was a lover of dogs and that is how we became acquainted.

In the course of our conversation he confided to me much about his early life. "But," he said, "I attained what I was striving for, and I am now on the fair road to success. The novelty of it is, however, that I owe it all to dogs."

Then he gave me the details; how he lived on a farm with his people and how he struggled for his early education until finally he came to that period when he was ready to enter college, but with no resources to take that step. "I had," he continued, "an Airedale bitch. She was the allround dog on the farm. I used her to hunt squirrels and rabbits with, but when it came to driving the cattle she was an expert. Later I bred her to a good dog and she raised a litter 
of eight puppies. I sold them all at an average of $\$ 25.00$ each. That gave me an idea. I bred her the next time and raised seven. These sold at a higher average than the first litter, but from this litter I reserved one female. I had a fund started for college and saw my way clear. Peggy, the old matron, had several more litters, all of which sold profitably, and later on Patsey, the daughter, presented me with a litter. I was going to college now, but the dogs were paying my way, for the folks at home looked after their interests, though I superintended the selling. I can truthfully say that I was sent to school by dogs."

The story of this young man also gave me an idea. If dogs were a paying investment for him on the farm, why not for others? This book is the result of the young man's story.

Dayton, Ohio.

The Author. 


\section{THE FARMER'S DOG A. F. Hochwalt.}

INTRODUCTION

A DOG for the farm; what shall it $A$ be? That is a question that may be answered largely according to one's own predilections in the matter, for there are a number of suitable, and profitable breeds. Naturally, it is assumed that the progressive farmer of today who interests himself in a dog for all-round farm work, or dogs for profit, will select a breed that will bring returns in both ways.

There was a time when any kind of a dog would do on the farm, just so he possessed a sufficient amount of intelligence to be amenable to the crude training necessary to make him a fair general service dog. Usually one of the varieties of the shepherd dog was the principal ingredient that entered into the composition of this nondescript of the farm and "Shep" 
was in most cases a long-coated animal, sometimes resembling the collie, sometimes the old-time drover's dog, which later became the fancy old English sheepdog of the show bench, but quite as frequently his general appearance gave evidence that was conclusive proof of the versatility of his mother.

It is quite true that many of these dogs, though entirely without pride of ancestry, were intelligent animals, but that is not extraordinary, for being a compound of many breeds they occasionally inherited a little of the best from all of them, although perhaps every other son and daughter of the litter from which they came, might have acquired all of the worst. Shep, however, was the bright exception and he went through life doing the work that was expected of him, sometimes proving to be a wonderful sheep and cattle dog, or even, if given the experience and frequent opportunity, developing traits of the bird dog, the foxhound or beagle. Many a nondescript dog of this class I have seen that was truly a wonder. 
When Shep grew old, however, and there was need of procuring a younger dog to help the old fellow out, then the great question arose how to find a successor. The chances of Shep reproducing himself were a negligible equation, for being a conglomeration of many breeds, the chances that his whelps might be anything from rat terriers to mastiffs were very good. The venture was too uncertain to even give it a trial and thus in nine cases out of ten Shep would pass out of life as the last of his race. What generally followed was the trying out of a dozen or more puppies, one after the other, before another was found which possessed the same degree of intelligence and sagacity as Shep, or more than likely, Shep was the one dog of a lifetime and could never be replaced, for no one knew how the elements varied that brought forth such a dog.

Conditions are changing on the farm, however; the demand for purebred stock is becoming more general and the intelligent farmer is no longer content with scrub stock. He insists 
upon owning thoroughbred cattle, swine and sheep, realizing that it costs no more to raise pure-breds than it does scrubs and he knows, further, that there is always a market for registered stock at far higher prices than he could ever hope to obtain for the nondescripts.

What applies to the other farm animals is equally applicable to the dog, and many of our rural neighbors have already discarded their mongrel dogs in the full conviction that a pedigreed dog or two on the place is a paying investment, not only in the financial returns, but also in the direct results obtained in service.

There is no gainsaying the fact that the demand for pure-bred dogs is becoming greater every year and there is no reason why the farmer cannot supply this demand as well as the specialist dog breeder. As a matter of fact, a pedigreed bitch of any of the fashionable and useful breeds will bring better returns in quick money than any other animal on the farm. Furthermore, such a dog is more susceptible to training and thus there is 
an advantage from the mere utility side of the question.

Naturally, there is no royal road to success, but the intelligent farmer or dog lover who has the inclination, may find dog culture a very profitable and interesting side line which will require but little additional time, and if proper discrimination is exercised in the selection of the foundation stock and ordinary intelligence in following the maxims that every dog breeder should have at least a passing knowledge of, then success is assured. To such as these, this little book may prove of some value. 



\section{PART ONE}

\section{Useful Breeds}





\section{CHAPTER I.}

The Airedale-Short History-His Possibilities as a Stock and Watch DogAs an All-round Sporting Dog.

I PLACE the Airedale first in the 1 list of useful breeds because he has become the dog of all nations. Not only is his popularity undimmed on the show bench, but he has also become the all-round dog for the stockman, the farmer, the upland shooter, the big game hunter; the wild fowler, the squirrel, the rabbit, the 'coon and the 'possum hunter, and then by way of variety he is also the playmate of the children, the watchdog and the companion for the automobile.

In referring to the Airedale, however, as the dog of a thousand roles, I have in mind the type bred from utility strains. There are a number of excellent bench strains whose usefulness has not been impaired, be- 


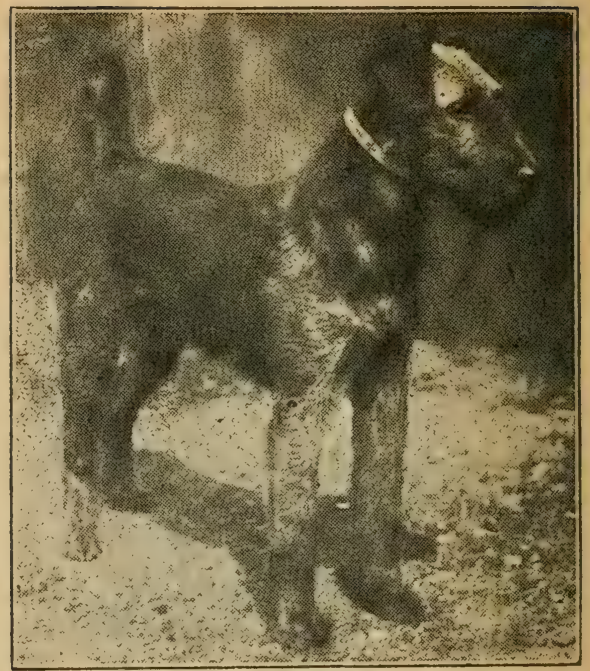

THE AIREDALE, "FURORE FIRST FLIGHT."

cause the members of the family are used continually for practical purposes, but on the other hand, many of the show strains have been so "improved," from generation to generation, and have had no work of any kind, hence much of the natural sagacity that is a heritage of the breed has been either bred out of them or lies dormant. The mad desire for 


\section{The Farmer's Dog}

"fine show points" has created havoc with many a useful breed of dog, and it is doing so with the Airedale in certain quarters, but thanks to the sportsmen of the country, there are still numerous families of the breed still bred for practical purposes, by men who consider utility first and bench wins as a secondary feature. For this reason the Airedale will always remain a working dog, or rather there will always be sufficient families to draw from in order to breed the service Airedale, even though some of the bench varieties are going the way of some strains of pointers and setters; namely, being bred for looks alone.

I do not mean that the man seeking for a practical strain of Airedales must disregard the essential qualities in the matter of proper coat, wellcarried ear, good color and varminty expression, but in making his selections, he must see to it that they come. from strains which have been used for practical purposes in all the various 
ramifications. Dogs coming from strains which never see the outside of their kennels except when going to and from shows, are not the kind that the farmer, stockman or sportsman will find lucrative to cultivate, for his market will be among those people who want a useful, all-round dog and not a show dog, sans brains and the capacity for service.

In making one's selection it is well to know something about the strain from which the puppies that one buys are descended. There are extremes both ways. In some localities one still finds Airedales ranging all the way from sixty-five to ninety pounds. Such a dog is too large to be shifty; it is therefore advisable to adhere to the lighter weights. Dogs ranging from forty-five to fifty pounds and bitches slightly less, are large enough even for big game hunting, such as bear, cougar, bobcats, etc. Furthermore, if they come from a game family they are really of more use than the extreme weights, first because 
they are shiftier and secondly, they represent less bulk. On the other hand, the undersized specimens running from thirty to forty pounds, are too small. Briefly, therefore, it is well to bear in mind that you select your stock from game, working strains which mature at something near the desirable weights specified.

Why is the Airedale the jack-of-alltrades among dogs? The question may be rightfully asked, for it is well to know something of his history in order to properly understand the dog. Briefly, he is a mixture of many breeds and at his fountain-head he was no doubt similar in many respects to the all-round farm dog, Shep. But unlike Shep, the Airedale was bred on in succeeding generations to his own kind, the most likely and typical specimens being utilized for that purpose, for in these early days, the Airedale was not yet commercialized and those pioneer breeders of the valley of the Aire, the place of his origin, had but one object in 
6

The Farmer's Dog

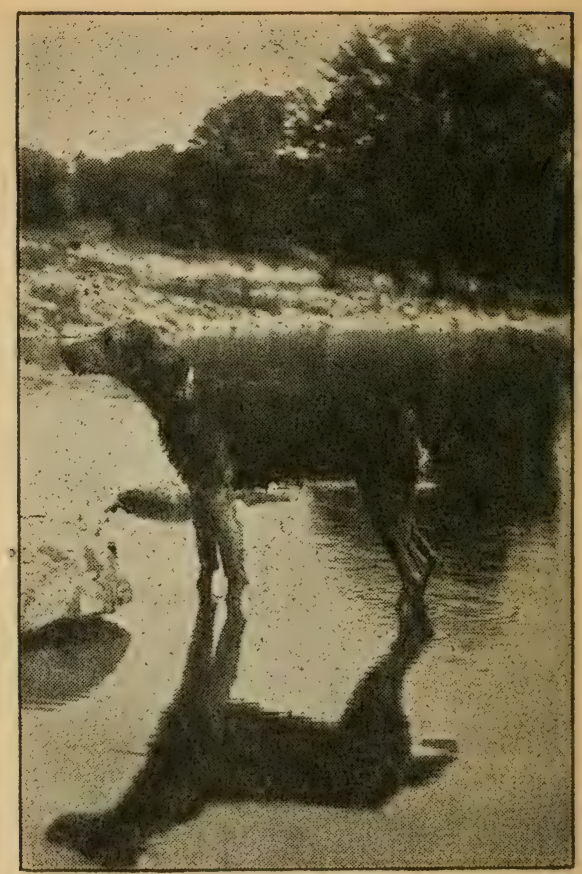

AIREDALE.

view and that was to produce a useful all-round dog, suitable as a companion for the home, and a satisfactory tyke for any kind of sport that might be available. Along the banks 
of the Aire and its tributaries there was always good sport in hunting the rats that infested its banks and many a Saturday afternoon's good sport was had by those hardy Yorkshiremen in making matches against their neighbor's dog. As a matter of fact, it became a regular field trial in which dogs were judged with as much seriousness as one finds in bird dog trials. Usually, a given stretch along the river was designated. Two dogs were put down together. The dog spotting the hole which contained a rat scored two points and the dog which made the kill, one, thus at the end of the stretch it was an easy matter to determine the winner. Even though those workmen were mill and factory hands they did not hesitate to back their favorites to the extent of their weekly wages on more than one occasion. In addition to the rats along the river banks there were the martins and the polecats, the badgers and foxes in the rocky fastnesses of the nearby hills and these also fur- 
nished a world of sport, for those Yorkshiremen were and still are sportsmen. If, by way of variety, one of those hardy tenants of the Aire Valley wished for still more excitement, there was the manor not far away and it was an easy matter to slip in upon these premises on a dark night when the keepers were unsuspecting, and take a hare or a pheasant, in which work the Airedale was taught to become equally adept. Again, there was the otter to be found in some of the streams occasionally, and fighting in the water is the special forte of the Airedale, for he comes to it by right of his heredity since one of his early progenitors is the otter hound. It was from the latter breed that the Airedale inherited his pily undercoat which is impervious to water, while from the terrier varieties that helped to make up his early ancestry, he received the wiry outer jacket that is also so essential. Indeed, even to this day one finds a throw-back occasionally to the 


\section{The Farmer's Dog}

houndy ears and yellow eyes of the otter hound that crop out now and then in the best of families. Breeding generation after generation of these utility dogs by selecting the best specimens of the locality, these hardy Yorkshiremen produced an allround dog with no thought of bench shows in those early days. Naturally there was still much variety of type, it is true, but there were few dogs bred that did not inherit all the intelligence and the sagacity of their manysided genealogy. If a worthless specimen was produced now and then, he was promptly discarded and thus eventually this breeding by selection had its good effects.

While it required a number of years before the fame of the Airedale spread to other parts of England, he attained a considerable local reputation and spread rapidly throughout Yorkshire, and there was scarcely a cottager living in that thickly settled manufacturing district who did not 
possess his tyke-or perhaps half a dozen.

It was along in the early seventies that the first show for Airedales was held at Otley. Naturally, those first shows brought together a heterogeneous lot of dogs with types as varied as they were entries, but this is only the natural sequence of mixing up various breeds into one. It was the same thing when, years ago, the much iauded so-called "Llewellin" setter was brought before the public. The Llewellin was a mixed breed at its foundation-head and the evidence of it was always apparent in the later generations. However, it is surprising what the Airedale breeders did in a short time. As a matter of fact, they succeeded much better than the setter breeders, for now type is about as well fixed in the Airedale as it is in any of the oldest of breeds.

Those shows at Otley did much toward attracting fanciers from other parts of England to see this newest and biggest of terriers. There was 
considerable controversy about the name; for a time they were known as Waterside terriers and again as Bingley terriers in honor of the town where they were supposed to have originated. Finally, however, after various experiments in the way of a name Airedale terrier was fixed upon, because it was really in the valley of the Aire and not any particular town in that locality where the breed sprang up. Terrier may be a misnomer because of the dog's size, for terriers are supposed to go underground for their quarry, but no matter how that may be, the dog has terrier traits and whether the word terrier is added or not, Airedale he will remain until the end of time.

Breeders of the south of England soon began taking up the breed after he once received his start in the North and it was greatly due to them that the breed became so well advertised. The English kennel club eventually recognized the dog as a distinct breed and show men of the south of Eng- 
land began "fining him down." Whether this was a good or a bad thing is a mooted question, but nevertheless it is a certainty that this assisted very materially in popularizing him. What kept the Airedale from going entirely the way of many of these "fined down" bench show breeds is the fact that he began to be taken up by sportsmen in all parts of the world. America soon became interested, and though we have our distinct line of demarkation in the way of working strains and pure show strains, the Airedale will ever remain the great all-round dog.

It is not my intention of going into a prolix history of the breed in this little book, but the interested reader who is desirous of knowing more about the breed and the many strains that are popular, is referred to an earlier work of mine entitled, "The Airedale for Work and Show." To the neophyte, however, a few words may not be amiss. If you are selecting dogs for all-round work, endeavor 


\section{The Farmer's Dog}

to obtain either puppies or young stock from strains that show the breed characteristics. Do not be too particular in getting the extremely long heads, narrow flat skulls and weak quarters and stifles which so many of the simon-pure show strains possess. Select a dog with good color, that is, black saddle and rich tan markings, with a short back, an abundance of bone in legs, well sprung ribs, a level mouth, small dark eyes and good strength of jaw. If the dog has the long head and the other show points, all right, but do not discard a sound specimen from a working strain for an unsound one, simply because he is a better show dog. The working dog is the one for which there will be a greater demand from the general public than the out-and-out show dog which may never be a service animal. In selecting bitches, size is not so essential, but procure one of the snappy, fiery kind with an abundance of terrier character that is absolutely game. It 
is from these bitches that the best results are obtained, for though they may be somewhat small, by breeding to a dog of good bone and substance, say, fifty pounds in weight, the general average may be maintained. Study the blood lines carefully. Ascertain everything possible about the family on both sides. Investigate whether or not the ancestors in the pedigree have been actual utility dogs and the more of these practical kind that are in the lineage, the more likely you are to succeed in perpetuating intelligent, sagacious and game Airedales. 


\section{CHAPTER II.}

The Collie-The Old English Sheepdog-Mixed Shepherd Breeds-The Shepherd or Police Dog.

THE shepherd dog in various forms 1 is unquestionably one of the oldest breeds of the canine species. We read of them in ancient literature and in the Bible they are referred to on various occasions. Whether the shepherd dog of those days was similar to the collie and other breeds of today is a question. The chances are, they were not, but built more like the old-time mastiffs of which we see prints in books of the middle ages. In those ancient days it was necessary to have a dog that could protect the flocks against the ravages of wolves, consequently he was a larger, heavier type of dog than we see today, except in parts of this country, and also in other lands where dogs of this class are still required. 


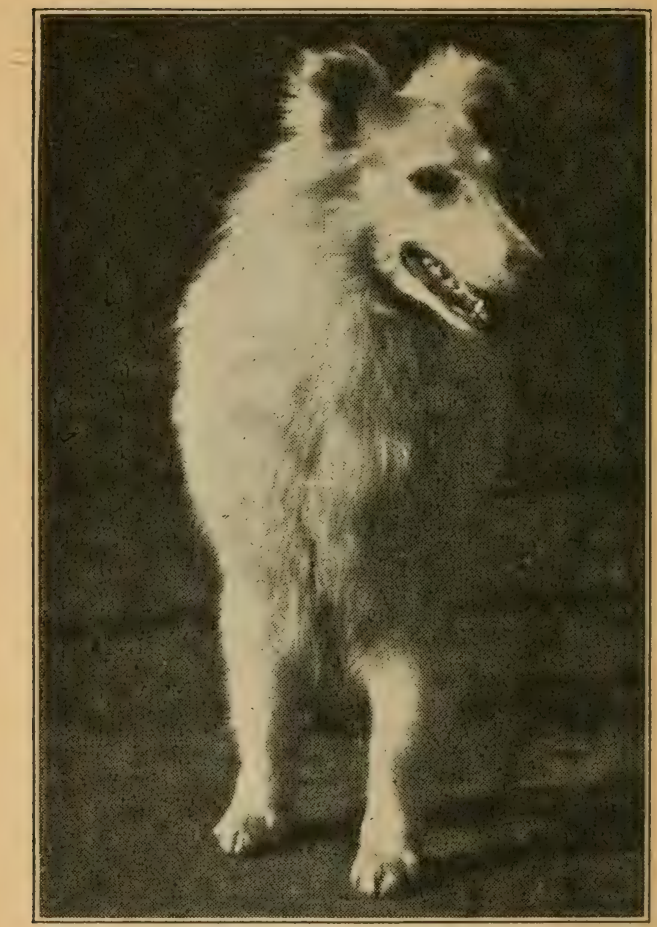

THE WHITE COLLIE JEFFERSON WHITE BABE,

The collie is pre-eminently the gentleman type of shepherd dog; a handsome, outstanding animal that attracts attention everywhere. Truth 
to tell, he has had so much attention focused on him that he has become the idol of the bench show fancier, and in. the making of a handsome, attractive show specimen, much of the usefulness has been bred out of him. It is simply a repetition of what happened to many other breeds. By nature the collie is an intelligent animal, though in many strains, generations of breeding for the fine points has in a great measure destroyed not only his usefulness as a stock dog, but has made of him a weakling. Fortunately, however, as in the.case of many dogs that have been made show dogs, there are always a number of people who still recognize the utility side of the animal and breed them for use, and it is from such as these that the farmer or stockman should select his specimens. The collies are easily broken to drive cattle, sheep, or in fact, any other live stock, and while one finds an impetuous specimen at times, as a rule they are 
very careful with their stock and do not rush them. Some say that the collie will never do this, but this is very much a manner of training. His master is his tutor. If the latter is rough and abusive toward the animals on the farm, the collie will soon acquire these rough traits; if on the other hand, he is properly taught from a youngster he will make a most

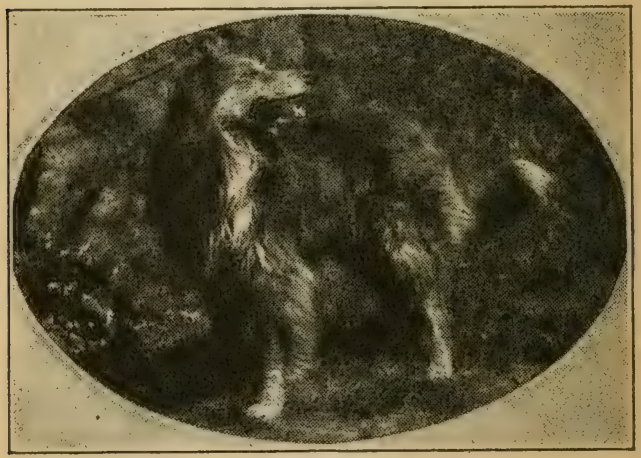

"SHEP," A SPLENDID COLLIE.

valuable asset. The collie has his faults, it is true, even those coming from real working strains, and these 


\section{The Farmer's Dog}

faults generally arise from his extreme restlessness and activity. The collie must have something to do. $\mathrm{He}$ will drive the chickens, he will stand guard over a flock of geese, he will be here, there, everywhere, poking his nose in this corner and that, forever on the move, and little transpires about the farm that he does not mix up in, especially when it has to do with live stock. Some are inclined to pick up quarrels with other dogs and in a scrimmage they usually hold their own, but the collie cannot, as a breed, be called quarrelsome. As a paying investment for breeding purposes, the breed is a most satisfactory one. Naturally the average farmer will want to breed dogs that are fit for work and not for show purposes alone, but that does not mean that he cannot breed good, typy specimens that will command fair prices. All colors are in demand: the sable and whites, tri-colors, blue merles, and the pure whites; the latter color in some localities is becoming quite pop- 
ular. As a rule one does not find the high quality show specimens among the whites, for it is extremely probable that other mixtures have been used in order to retain the pure white color, but however that may be, those I have seen of this color were extremely intelligent, and what is more, seem to be gaining favor rapidly.

In this connection it might be said that in many parts of the West and also in Canada, the collie has been crossed with other breeds for the purpose of creating a stronger dog. In doing this they also produced intelligent animals. These sheep dogs of the northwest would not pass muster on the show bench, but when it comes to a useful animal they are very sagacious. However, dogs of this class, not being pedigreed, nor breeding true to type, would scarcely command prices that are paid for purebred stock. The farmer wishing to take up the collie for profit would better stick to the pedigreed animal descended from strains that are 


\section{The Farmer's Dog}

known to be working dogs, and in doing this he will have the kind of dog that will be useful, not only on his own place, but command a good price on the market.

Some years ago the so-called smooth collie seemed to be gaining favor in this country, but with the rapid rise of the shepherd, or police $\mathrm{dog}$, the desire for this breed waned. No doubt the name, smooth collie, is a misnomer, but it is recognized by this name in the American Kennel Club classification. This breed is in reality a nearer descendant to the old-time sheep dog than the rough-coated collie. While his origin is left greatly to speculation, his appearance and his temperamental characteristics seem to indicate that he may be a modern evolution of the old-time "mastins." $\mathrm{He}$ is said to be very sagacious and makes an excellent stock dog, both as a driver and a guardian of the flocks.

In England and Scotland he has always been more popular than here, 
though no doubt, if some enterprising breeder would take up the breed in America, and show his qualities as a workman, it might soon be popularized, despite the present popularity of the shepherd or police dog.

The Old English sheep dog was originally a real working dog, but the kind we meet with nowadays would scarcely fill the requirements of the practical farmer. $\mathrm{He}$ is a large, square-headed dog, with immense coat, which requires endless time to keep in condition. No doubt the present-day type is a very much exaggerated "improvement" of the old drover's dog, but if these present-day specimens as seen at bench shows are of any use now, I have yet to see it demonstrated, although it is said that here and there they are still used for practical purposes. There is a certain demand for the Old English Sheepdog and no doubt all the puppies that could be raised might be easily sold, but the breed is a difficult one to care for and the returns 


\section{The Farmer's Dog 23}

for the trouble would be small as compared with other breeds.

- The shepherd, or police dog, formerly known as the German shep-

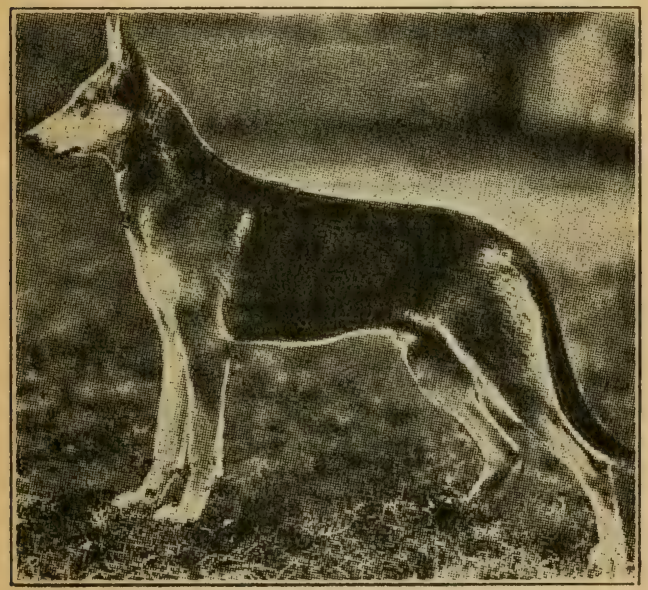

IMPORTED ARGUS VON BLASIENBERG.

herd, is one of the most popular breeds of the day and as he is an intelligent, as well as a handsome animal, he bids fair to retain his place in popular favor for some time to come. This dog, in many respects, 


\section{4 'The Farmer's Dog}

resembles the Airedale for manysided qualities, though, of course, he is a dog of entirely different type. Unless the bench show element ruins the breed, it should become a very useful one for all purposes. Perhaps he is not the specialist in stock driving that the collie may be, although I have heard of isolated cases where he proved to be equally as good as the best of collies. The shepherd dog has other uses, however, that make him a practical dog for the farm as well as the city or the suburban places. He is a first-class watch dog and can be taught to run down criminals or hold them after he brings them to bay. $\mathrm{He}$ is rightly called a police dog, for he can perform many of the duties of the human policeman as sagaciously as the latter. $\mathrm{He}$ knows no fear; his excellent nose leads him to detect the presence of strangers, his acute hearing is almost uncanny, for he will hear the slightest noise that would escape his human master entirely. He possesses great 


\section{The Farmer's Dog}

strength and can hold any criminal that may be cornered, and if it is necessary to trail a criminal, he is almost as expert as the bloodhound, especially after he has had training along these lines. As previously stated, the dog is very intelligent and may be easily taught any of the accomplishments of police duty as well as the art of taking care of stock on the farm. In respect to sporting instincts, the Airedale has, of course, the advantage, for the latter can be used for hunting furred and feathered game which the shepherd is scarcely fitted for. I have heard it said that occasionally isolated specimens of the breed could be taught to run rabbits or tree by night and day, but this is not a characteristic of the breed, hence one must not expect too much of them.

The shepherd has a wolfish appearance, with high set prick ears, narrow muzzle and wide skull. In height the males run from 22 to 25 inches, 
26

The Farmer's Dog

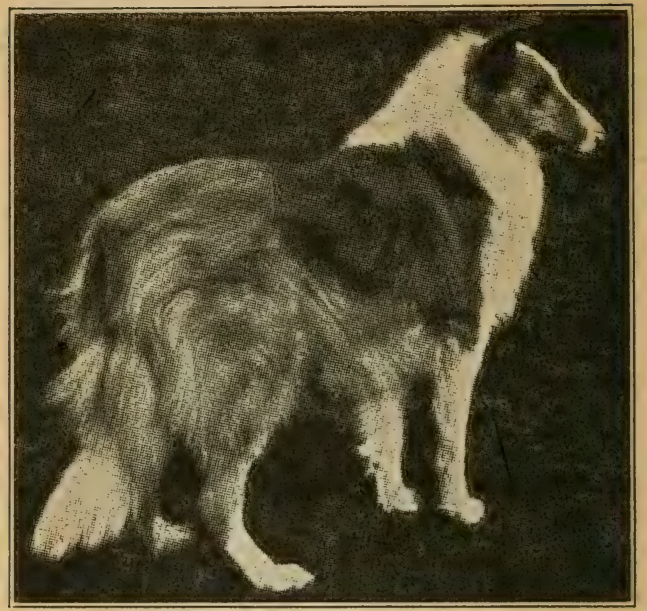

THE ROUGH-COATED COLLIE CH. EASTWOOD ENSIGN.

A Modern Bench Show Collie.

the standard calling for 26 inches as the maximum; those over that height are considered too large. $\mathrm{Fe}-$ males should run from $211 / 4$ to $231 / 2$ inches, with 24 inches as the maximum. Naturally, the fancier who is interested in utility alone, will not be so much concerned in drawing the question of size too closely, though 


\section{The Farmer's Dog}

dogs that are too large are lacking in shiftiness, while, on the other hand, if they are too small, they are unable to cope with the enemies they are called upon to meet.

The Shepherd should stand up squarely on straight front legs when viewed from all sides. The hind legs should have sufficient bend in the stifles to give quickness in action, but there must not be too much sweep from hip to hock. The jaws must be strong, with lips tight and dry and not hanging over in flews as is the case with hound varieties. The teeth must be large and strong, meeting evenly and not under or overshot. The smooth-haired specimens are preferred though one encounters rough or wire-haired ones occasionally, and also what are known as long-haired varieties, though the two latter are not met with commonly. By smooth-haired is meant coats about two and a half inches in length, 
the outer coat stiff and straight, but lying close to the body. The head, including inside of the ears, front of the legs, paws and toes are covered with short hair and the neck with longer and thicker hair; slight fringe on the back of the legs is desirable. The color varies: black, iron-grey, reddish tan, reddish-brown (either entirely of one color or with regular markings of reddish brown with whitish grey); pure white, white with dark spots (harlequin), or black clouding on grey, tan or light brown with the so-called wolf markings, or with white markings on breast and legs.

When running the dog should move evenly and harmoniously, the strides being long and elastic, lifting the feet only just clear of the ground. It is in reality the wolf gait and in view of the fact that the dog resembles the former so much, it has been said that this is an objection in the West and Northwest, where wolves abound, 


\section{The Farmer's Dog}

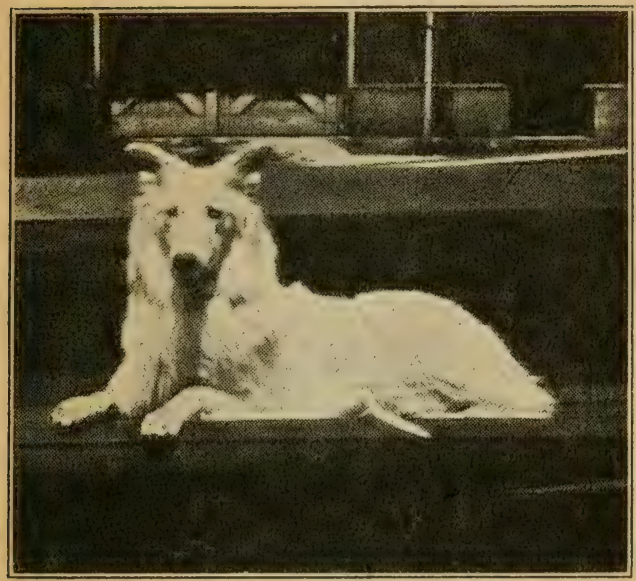

THE WHITE COLLIE JEFFERSON WHITE LASSIE,

as the shepherd may easily. be mistaken for a wolf when he is seen from a distance. The chief qualities of the shepherd dog are his intelligence, alertness, loyalty, gentleness, courage, obedience, willingness and devotion. All of this will show in the animal's general appearance.

The demand for shepherds being so great at the present time, the first 
cost of obtaining good specimens is rather prohibitive, but the up-to-date. fancier wishing to make this breed part of the farm's earning capacity, will find the breeding of them, even though it is done on a small scale, a lucrative investment. 


\section{CHAPTER III.}

Other Useful and Profitable BreedsBird Dogs and Hounds.

$\mathrm{IT}^{\mathrm{T}}$ is not every farmer who is in1 terested in dogs of the pastoral types. Many are situated in places where stock raising is but an infinitesimal part of the farm's industries, and again, many are in localities where game of all kinds is plentiful. To such as these a dog of one of the sporting varieties might find a greater appeal than any other breed.

Sporting varieties are always in demand; there is no rise and fall in fashions, consequently the farmer taking up pointers, setters, beagles, fox, or coon hounds, will always find a market for his surplus stock, not only among his own class, but also from the city sportsman and the field trial enthusiast. There is no question but sporting dogs can be raised and brought to maturity much more successfully on the farm than in any 
of the large kennels, especially if the farmer confines his breeding operations to a limited scale of from one to four litters a year. Under such restrictions the work will not become irksome, neither will an expensive kennel equipment be required.

A farm-raised pointer, setter or hound has all the advantage over the kennel-bred product. $\mathrm{He}$ is raised largely according to the nature method; he has more freedom from the day he opens his eyes, and he grows up in an environment that is in keeping with his instincts and inclinations; he learns to self-hunt by independent forays with his mother while still young; he acquires the ways of the woods and fields and he learns from actual experience where to go to find game. Put down a bird dog of a year old that has been raised in the country with one of the kennelraised kind and note the difference in the wisdom displayed. The kennelbred youngster without any experience is in a new environment; every- 


\section{The Farmer's Dog}

thing is strange and he seems cowed, while the farm puppy is all confidence and decision, born of his constant association with the things of the outdoors. From personal observations I am convinced that the farm-raised puppy is farther advanced at twelve months of age than the average twoyear-old kennel-raised product. That is why the average sportsman or field trial patron prefers to find his young stock on the farm. He knows that such a puppy has been started properly and that his physical and mental development have taken place under natural conditions.

What applies to bird dogs is equally applicable to beagles and other varieties of hounds. The average beagle, raised on the farm, is a rabbit dog at one year old and frequently younger, hence, when the city sportsman purchases such a puppy he is equipped to go afleld with his dog at once and obtain considerable satisfaction in shooting over him. Not many years ago I spent one of the 
34

The Farmer's Dog

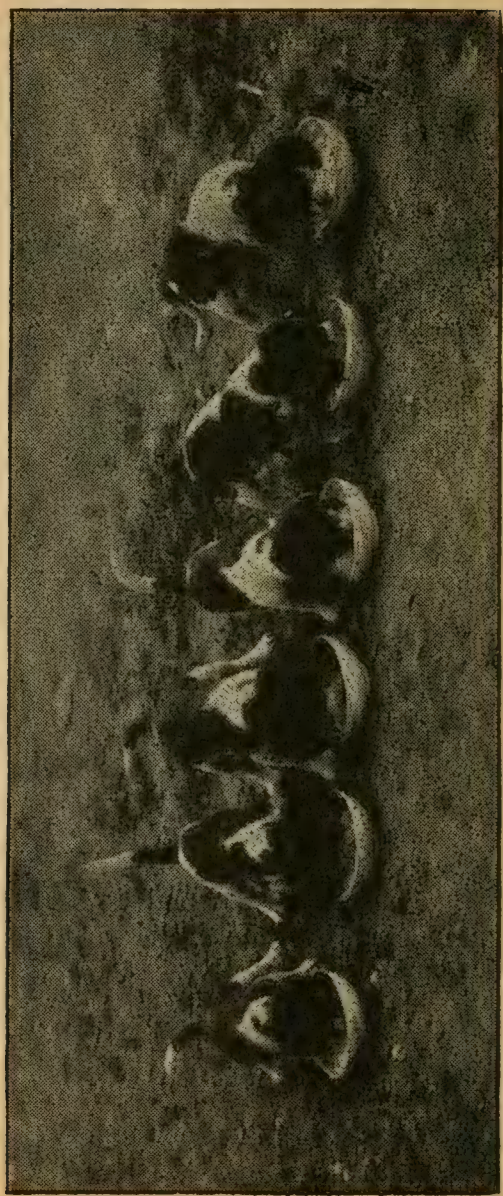

हึ 
most enjoyable days in the field-rabbiting with a pair of farm-raised beagles-that I ever had at this kind of sport, and yet these beagles were but eleven months old at the time. They had a world of experience, however, and knew more about rabbits than many a three-year-old.

All trainers of either bird dogs or beagles will freely confess that they would rather take farm-raised pupils to train than any of the kennel-bred ones, for they realize that half the work is already accomplished and all that is necessary is to teach such animals how to hunt to the gun, and the finer accomplishments of the finished performer.

Such being the case, no one living on a farm who has an inclination for dogs need fear to take up these breeds as a profitable investment and as a means of recreative pastime, for there are many months during the fall and winter season when work is light and the call of the wild is insistent. 


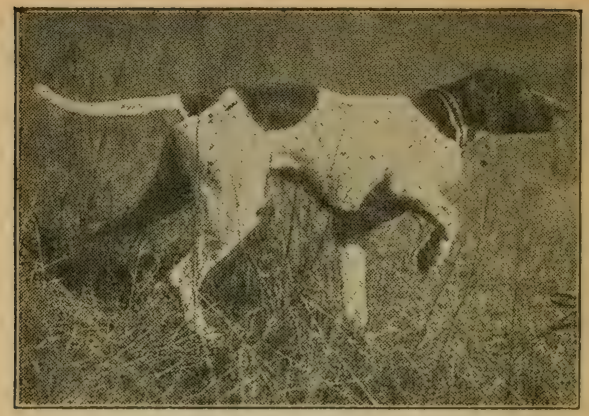

POINTER.

The question of what breed to select is very much a matter of individual preference and what the buyer's predilections are in the way of sport. If he is fond of upland shooting, any of the setter breeds, or a pointer, or possibly a wire-haired pointing griffon will appeal to him. If he is a rabbit hunter then nothing would be more satisfactory than the beagle; if it is night hunting, then the 'coon or 'possum hounds are desirable; or if it is fox hunting, then naturally nothing but fox hounds would interest him.

Perhaps the bird dog breeds are 
the most lucrative. That is, puppies from these breeds demand higher prices, generally speaking, than beagles or 'coon hounds. In selecting a pointer or a setter strain, however, it is well to study the various families in order to have those that are in demand. As far as pointers are concerned, no beginner can go far wrong in selecting any of the strains now before the public.

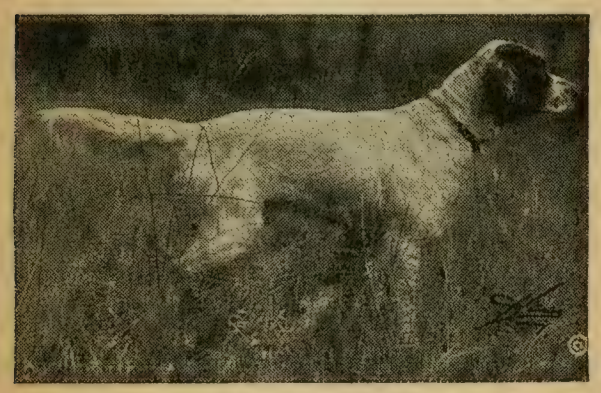

SETTER.

In English setters, there is more or less confusion caused by the so-called $100 \%$ Llewellins which, I might say in passing, has done the set- 
ter much more harm than good. I do not mean that the Llewellin strain is not a very excellent one. The damage was done, however, by breeders who insisted upon breeding the $100 \%$ dogs simply because they were hundred per cent, regardless of individual quality. Whether they are Llewellins or so-called grades (which is also a misnomer), they are all English setters and if the pedigree is right, as it must be if the stock comes from pedigreed dogs, then it is mainly a question of selecting individuals from strains that are known to be good, and it is immaterial if they are Llewellins, so-called, or English set- ters. Although the fad that has swept the country creating a demand for Llewellins has caused prices for the $100 \%$ dogs to soar out of all proportions, it will be found that it is the so-called grade English setters which have really maintained the laurels for the breed in field trials as against pointers, hence the breeder might as well disregard the names of strains 


\section{The Farmer's Dog}

and go in for real dogs. By doing this he will breed successfully. If he can find a good individual brood matron that is $100 \%$, all well and good and if he is able to find a sire that is also of the same percentage then he is well started, but it is far better to select good individuals of so-called grade stock than to decide upon second rate $100 \%$ dogs.

The novice will probably ask the question what is a Llewellin? The accepted dictum is that they must descend in unbroken lines from the Laverack strain of more than fifty years ago and the Duke-Rhoebe cross. Any dog that has any other outcross is not a Llewellin, though as a matter of fact, he may be much better bred, for it is a well proven fact that the Duke-Rhoebe cross was a mixed lot at its source. Possibly it was this very cross of strong, vigorous blood, blended with the inbred Laveracks that was no doubt the potent factor in these early so-called Llewellins and the farther we are get- 
ting away from the source the more attenuated this blood becomes, consequently the logical thing is to breed to the best to be found among the setter strains regardless as to whether they are called Llewellins, grades or English setters, for when all is said, they are every one of them English setters, and the wise breeder will bear this in mind when he makes his selections. The reader wishing to go further into the question of pointer and setter strains, is cited to my two previous works, "'The Modern Pointer" and "The Modern Setter."

The wire-haired pointing griffon is in reality a rough-coated pointer, which had his origin in Belgium, France and Germany. He is a slow, methodical dog, with an excellent nose. He is easily broken as an upland hunter and as a retriever from land and water. He lacks the speed, range and style of our present-day pointers and setters, but there seems to be a popular demand for the breed 
and good specimens are commanding high prices.

Beagles do not bring the prices of the bird dog varieties, but they are less costly to raise and do not require the room, hence when one takes everything into consideration - the sport they give one and the returns from surplus stock - they prove very satisfactory. At the present time beagling and beagle trials are becoming more and more popular, hence the trend toward higher prices for good stock seems to be the prevailing note.

Foxhounds of the well-known strains-American strains-such as the Walker, July, Trigg, Williams, and others, always hold their own, for foxhunting will remain a southern sport until the end of doom. As for 'coon hounds, these are generally more of a nondescript variety; as a rule, descendants of the various foxhound strains, sometimes mixed with various blood. Puppies do not command the large prices of the registered 
breeds, but a well broken 'coon hound is always in demand and the same may be said of 'possum dogs. Several years ago, while hunting in the south, I saw a northern enthusiast pay $\$ 200$ for an unpedigreed, plainlooking, tan-colored hound, simply because he was a real 'coon dog. 


\section{PART TWO}

\section{Breeding, Care, and Marketing}





\section{CHAPTER I.}

Breeding Dogs for Pleasure and Profit - General Hints - Importance of Pedigree and the Knowledge of What it Represents.

THERE is pleasure and profit in 1 breeding dogs. The returns are quick, the bringing up of puppies interesting, and on the whole, one discovers a fascination in the various phenomena that keeps one fascinated.

To the aspiring breeder, however, I would say, gain as much knowledge of the subject as possible before attempting to rear puppies. It is not an undertaking for the person who imagines that all that is necessary for success is a pair of dogs. You must have a clear knowledge of what you set out to do, weigh the various influences at work and their probable effect on advancing or retarding the object you have in mind, and act accordingly. 
In a work of this limited nature I cannot go into full details of the various phases of the breeding question, but I may point out a few guide posts to success, as it were, that may serve as axioms, which should be kept in mind. Naturally the novice, after he once becomes more deeply interested, will discover new experiences and come to conclusions of his own, and while he is learning this, he may study the various works on the subject to good advantage also.

The old saying "like begets like" is good as far as it goes, but one must not take this in a too literal sense, for the ancestry behind the two individuals mated, play a very important part, hence the saying must only be considered in conjunction with other laws and influences at work.

Breeding back, reversion, or atavism, as it is scientifically called, is always a factor in breeding operations and frequently sets at naught the like begets like theory. Atavism means simply reverting back to a re- 
mote ancester, as for instance, the offspring may resemble a great grandparent or some ancester still farther back than that. Hence, if somewhere in the ancestry there has been some violent outcross, it is likely to appear again, even after the lapse of many generations. This has been shown in various breeds at different times, as for instance when the bulldog was crossed with the greyhound a number of years ago in England, in order to give the latter more strength and courage, traces of this cross were seen in greyhound ancestry seven generations after this one cross had been made. It is the same with other breeds. In setters we very often find a specimen that is an exact counterpart of some of the very earliest dogs in Llewellin (so-called) pedigrees.

In Airedales we find frequent reversions to the hound ears and light eyes of the otter hound. In Bostons we find numerous throw-backs and so on adfinitum. All this suggests that we must have a thorough knowledge 
of the ancestry of our stock in order to breed intelligently.

We can do this only by breeding from parents whose pedigree is not only available, but of which we have made such a study that we are fa- miliar with each name in the breeding and what it stands for. If we are breeding Airedales for utility purposes, we want to know first of all, that the sire and dam are of the right sort individually. Then we go back into the next generation and learn all we can about the grand-parents If there is a weakling here we should know it, in order to figure the possible chance of his ancestors traits cropping out. Assuming that the generation of grand-parents seems to be all that we are looking for, then it is well to take $e^{c}$ p the great grand-parents, and so on. Naturally the farther we get back in the pedigree the less infiuence each individual ancester will have on the offspring, but a certain percentage, nevertheless, will figure in the general summing up. 


\section{The Farmer's Dog}

In this respect the law of ancestral heredity as expounded by Sir Francis Galton, and amplified by Pierson, is a very good guide. Naturally, the theory is far from infallible, but on the whole it is a safe theory. Simply stated, this law endeavors to prove mathematically the fraction of direct inheritance; that is, the similarity of the offspring to its various ancestors. From his observations Galton comes to the conclusion that the visible dominant characters of the progeny correspond on the average with those of the various ancestors about as follows:

From the immediate parents, $50 \%$.

From the grand-parents, 25\%.

From the great grand-parents, $12.5 \%$.

From the great great grand-parents, $6.25 \%$.

Earlier ancestors in proportion until the figures are carried to infinity; thus accounting for the total heritage. It should be borne in mind, however, the characters referred to 
50

$$
\text { The Farmer's Dog }
$$

are the visible ones and do not apply to temperamental characteristics which, in dogs, are factors whose importance is unquestionable.

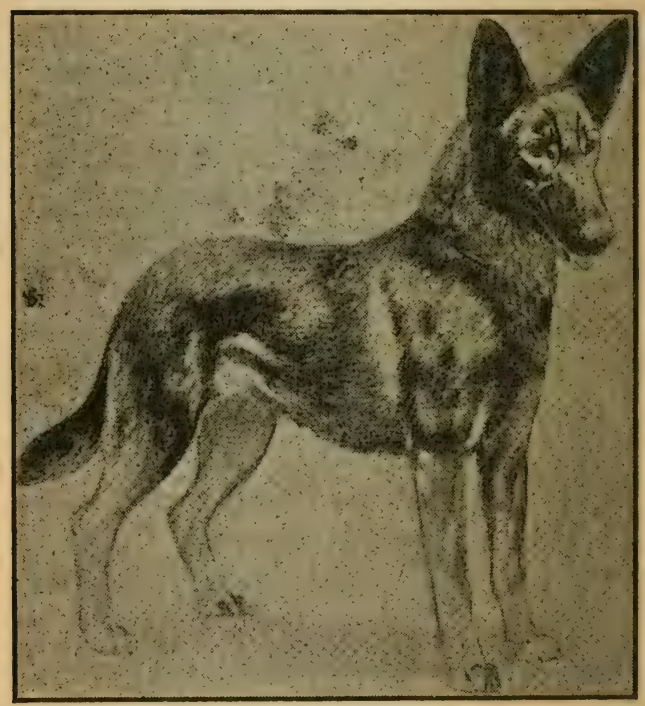

WINTERVIEW PATRICIA VON FLUGELRAD,

That is another reason why it is necessary to know all about the dogs that go to make up the pedigree of 


\section{The Farmer's Dog}

the prospective parents. In some strains one is prone to find certain - physical weaknesses that are transmitted from generation to generation. Dogs of a cowardly or highly nervous temperament are not likely to produce good utility offspring. Others might be affected with a constitutional disease which one does not care to see transmitted in the offspring, and if the breeding is in the least close, these faults are likely to be intensified in the same proportion as the good qualities are intensified. It is easy to understand, therefore, why it is all essential to know the line of blood one is using.

This brings us to another phase, and an important one, in the reproduction of animals under domestication. This is line-breeding, in-breeding and cross-breeding. By linebreeding is loosely meant the system of breeding within the limits of the family, as cousins, uncles, aunts, etc., but not too closely. In-breeding is mating son to his dam, or daughter to 
her sire, while in-and-in-breeding is the mating of brother and sister. On this subject I am going to quote from my previous work, "Dogcraft":

"The evil effects of in-breeding have been discussed so much that many breeders, and the public at large, have begun to look upon it with greater aversion than is really necessary. Occasional in-breeding is absolutely essential under some circumstances, but it requires nice discrimination to determine just to what extent this may be practiced.

"The good effects of inbreeding are uniformity of type, smoothness of finish and retention of character. These qualities can be attained in this way much more readily than otherwise. The evils require more time to detect, but when in-breeding is long continued, it usually results in weakened constitution, susceptibility to disease, impotency, loss of stamina and size. Breeders of wide experience maintain that in-breeding may be practiced without fear of evil re- 
sults for two or three generations, provided the sire is bred to daughter, or mother to son, for in these cases the sire or dam only crosses with onehalf of his or her own blood, and the advantages so gained outweigh the slight loss in constitution or vigor.

"The crossing of brother and sister is known as in-and-in-breeding, and, as the blood is identically the same on both sides, it follows that evil results will appear much more quickly. When two closely related individuals are brought up and exposed to different conditions of life, the results of such a mating will generally prove much more satisfactory, for it is a well known fact that the environment under which animals have been brought up, such as differences in soil, climate and manner of feeding, effects almost as great a change in the constitution of the progeny as would result in the infusion of new blood.

"In-breeding should be discontinued as soon as the first signs of evil effects appear. 'Then it is wise to re- 
sort to an outcross. Naturally, many breeders who, after a number of years have succeeded in building up a strain, hesitate to resort to an outcross for fear of introducing undesirable qualities, but when loss of mentality and sterility once make their appearance, then it is necessary to do so. Many cases are known where strains of cattle, sheep, hogs and other animals, which, through inbreeding, had suffered in size and also had become perfectly sterile, when bred to their own kind, immediately regained these qualities by the introduction of outside blood. Therefore, the results of an out-cross became apparent much more quickly, as before stated, than the evils of inbreeding. Among most breeds of dogs of the present day there is no necessity for close in-breeding, unless it is desirable to intensify some particular qualities, but when these are obtained it is best to resort to outside blood-a violent out-cross is not at all necessary-and a return to size 
and stamina will soon be noted as the result."

- The old theory of telegony, or the influence of a previous sire, has about been discarded, although even at the present day there are some breeders and even a few scientists who still hold that once dog has made a misalliance and had a litter of puppies by a mongrel or a dog from some other breed, all future litters will be affected by this occurrance in that certain puppies of the subsequent litters coming from sires of her own kind will resemble the mongrel cross. No clear proof has ever been brought forward to substantiate this theory, hence I have always taken it for what it is worth. However, it is best to be careful that such misalliances do not occur, for even though future litters may not be affected it is certain that immediate results are thus ruined.

Prenatal impressions is another subject that is not given much credence at the present time, although up until late years the belief was 
56

The Farmer's Dog

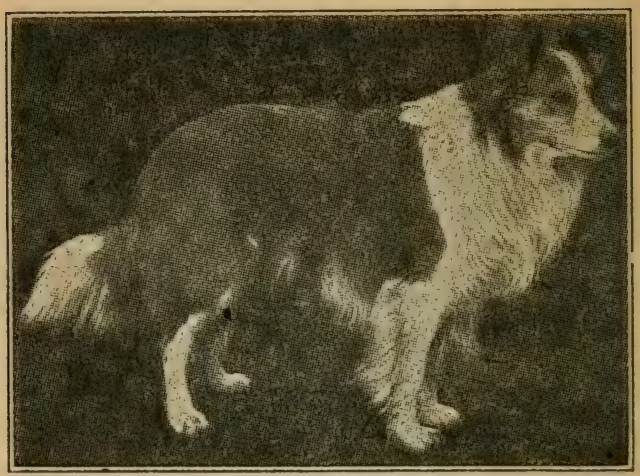

THE ROUGH-COATED COLLIE CH. METCHLEY WONDER,

The Old Type Bench Show and Working Dog.

widespread that impressions made upon the mind of the mother during the period of gestation will influence the ultra uterine development of the young and cause birth marks, abnormalities or color changes. The theory no doubt arose in the Biblical story of Jacob and the sheep flocks, of his father-in-law, Laban. Jacob was to receive sheep of certain colors as his own. In order to breed these colors Jacob set up colored rods in the field where the sheep grazed and thus the 
ewes were to be influenced; and according to the story, Jacob was a success in breeding for color. Since that day, however, we have heard of no such successes in color breeding when but such simple methods were employed. I know of a setter breeder who some years ago wished to breed his bitch to an orange and white dog, but wanted to get the white, black and tan colors in the offspring, for at - this period the orange and whites had not come into the popularity that they now enjoy. To achieve this result he confined the bitch in a kennel adjoining that of a dog which was beautifully marked white, black, tan and ticked. When the time came for breeding, however, the orange and white dog was used. When the puppies were whelped, all but one were orange and white; from this it will be observed that for once, Jacob's theory did not work out.

No doubt the birth marks or deformities are due generally to an inflammation of the uterus, because of 
arrested foetal development caused by pressure from the ligaments from the uterus or umbilical cord. Naturally the habitual mental condition of the mother while carrying her young has a certain amount of influence upon the fluids nourishing the embryo, though this can scarcely be regarded as a direct mental impression upon the foetus during the process of development.

The breeder who wishes to go still further into the subject of dog breeding will find a more elaborate treatment of the subject in my previous work, "Dogcraft." 


\section{CHAPTER II.}

The Stud Dog and the Brood MatronOestrum-When it Occurs-Time for Breeding-Care of Matron During Period of Gestation-Parturition.

THE average small breeder will do 1 better not to attempt to own his own stud dog, unless he should secure one that he can also offer to the public, for if he is breeding but one or two, or even half a dozen bitches a year, he will find it more satisfactory, and. even more profitable to pay a stud fee and select that kind of dog which will suit each of his bitches. One dog may nick very well with one bitch, because of blood lines, conformation, temperament and all other essentials, but will not answer so well with the others, hence it will readily be seen how much greater the advantage is. Furthermore, when one breeds to a dog of known reputation the puppies are just that much more valuable. 
In making your selection of a stud dog, study the bitch that you wish to breed to him; look over the two pedigrees carefully, compare the blood lines and if these look logical-that is, if the combination in theory seems plausible, then find out all you can about the dog and whether he has any glaring faults, or is prone to transmit any constitutional disease or weaknesses. If all these qualifications are satisfactory, ascertain if he is a working dog, for I am assuming that you are breeding dogs of prac- tical value. If you are breeding cattle or stock dogs, see that the prospective sire comes from a service strain, and if he is himself a broken dog, all the better. If you are breeding Airedales for all-round gameness, have nothing to do with a stud dog that is a weakling mentally and a coward physically. Better sacrifice some of the show points for courage, intelligence and sound conformation. Never breed to a dog with weak back, loins, quarters or stifles. Type is of 


\section{The Farmer's Dog \\ .61}

course essential, but type drawn to extremes, that is, type and quality over physical and temperamental excellence are the two things that have done harm to many of our best breeds'

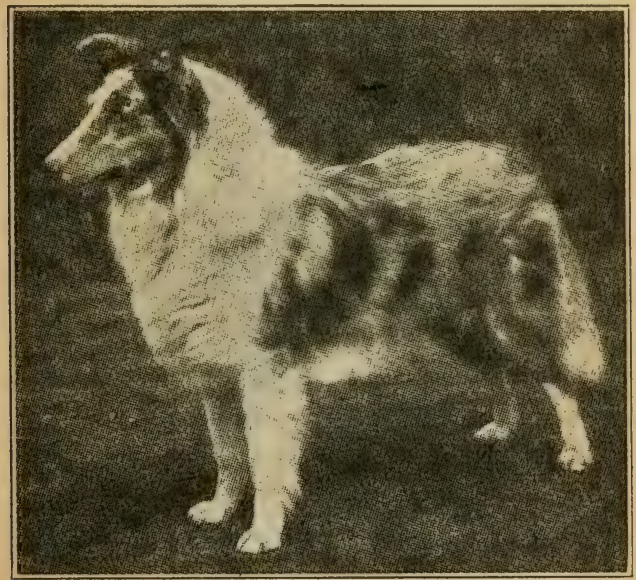

THE BLUE MERLE COLLIE, HANDSOME BLUE BOY.

In short, when selecting a sire to breed to your matron, keep in view the idea that you must find a dog that is especially strong where your bitch 
is weak, but also it must not be forgotten that this dog must come from a family whose members are habitually strong in these parts. For instance, you might select a dog that is especially good in head, but whose sire and dam were bad and this specimen is one of the exceptions due to atavism. He may resemble one of his remote ancestors, but not be able to sire his own kind. Keep the general average of the pedigree in mind.

In selecting bitches for your prospective doggy venture, decide first upon the breed, and after doing this you will do better by adhering to that breed. You will be enabled to study one variety and come to understand it more thoroughly than if you were to dabble in various breeds. Whether your selection be one of the pastoral varieties or one for sport, try to learn all you can about it and study your own individuals. It is not necessary to select show types, as I have already pointed out, but rather buy good, sound puppies from stock known to 
possess the characteristics which you wish to perpetuate. If you wish to begin breeding at once, it is well to buy matured bitches, but it is far better to begin by securing a few bitch puppies and allow them to grow up on the place. Thus you are enabled to train them to do whatever work they are fitted for and they are more likely to give satisfaction. Select carefully, not from show, but from good pedigreed stock. Many a so-called "waster" proved to be the best kind of a brood matron, producing offspring that afterward proved to be marvels of their particular breed. Allow the puppies to grow up in freedom, for the bitch puppy that is brought up in this rough and ready fashion, will need very little attention when the various crises of her life occur.

There is no particular time at which the period of oestrum or season, in the female of the canine species may be looked for. Much depends upon the breed; the toys and 
small varieties usually coming in season at any time after they are six months old. Pointers, setters, Airedales, collies and shepherds may come in the first time between eight months and a year, or even go longer, but I have found the general average period to be between ten and twelve months. After the bitch has been in season once, she should, normally, come in again every six months, though this varies in certain individuals, some coming as frequently as every four months, while others may go eight, and even twelve months, though as I have said in normal condition, the time between periods is six months.

Personally, I have seen very excellent puppies from bitches that were bred their first season, though this is not to be recommended unless the bitch is particularly well developed and the first period does not come much before she is a year old. The generality of breeders, however, wait until the second season. The owner 
must be governed by circumstances both in this matter and also the frequency of breeding in later years. A bitch can have two litters a year if she is normal, which also means that she must be vigorous. Two litters within twelve months, however, is a considerable drain on the system, and may result in loss of vitality and eventually the loss of the bitch, so here again the owner must be governed by circumstances. The hardiest breed I have encountered in my experience is the Airedale. The females of this variety usually have large litters and seem to raise them successfully every time. I know of one Airedale bitch which had four litters within two years and each litter averaged ten puppies; in other words, she raised to weaning time, forty puppies in a period of twenty-four months and did not seem to be any the worse for it. The owner should always bear in mind that he is the judge in such matters; if the bitch shows signs of debility or loss of vitality after raising 
a litter she should be given a rest, if on the other hand, there is no impairment of her strength or general condition, she may safely be bred each season for three or four consecutive periods, at all events.

Care must be taken upon the approach of the period of oestrum that the bitch is promptly isolated. That is, she must be placed in a building out of which it is impossible for her to dig, or into which no dog will be able to enter, either underground, through windows or doors. The better plan is to keep the bitch in an upstairs room or loft that is entirely inaccessible, for it is surprising how quickly the dogs of a neighborhood will discover a bitch in season and what cunning tricks they will resort to in order to gain access to her.

The owner, even though he be a novice will soon recognize a change in the bitch when the period of oestrum approaches even though there may be no physical evidence. Her temperament will be changed. Timid 


\section{The Farmer's Dog}

bitches usually become bold and not infrequently, a savage or unruly one will be very docile. An enlargement of the external genitals will appear about this time and accompanying this will be the discharge of a whitish fluid, which increases in quantity and becomes tinged with red until it is eventually a discharge of pure blood. The entire period of oestrum extends over a period of about twenty-one days, but it is generally during the second week that the swelling subsides, the discharge lighter in color and finally disappears about the fourteenth or fifteenth day. This is the best period to have the service performed; that is, between the fifteenth and twentieth day. If she is to be shipped any distance, the owner will do well to have his arrangements made with the owner of the stud dog, some time in advance and as soon as she shows signs of being in season, she should be shipped, for the strangeness of surroundings, the shipping, and the life in the crate have a certain 
68

\section{The Farmer's Dog}

effect upon her and she should have several days of quiet before she is bred. If the time is right, one service is sufficient, though many breeders prefer two, given one day apart. Personally I have always found the results just as satisfactory from one service, provided everything was normal.

If the owner of the stud dog returns the bitch immediately after service, it is well to keep her confined another

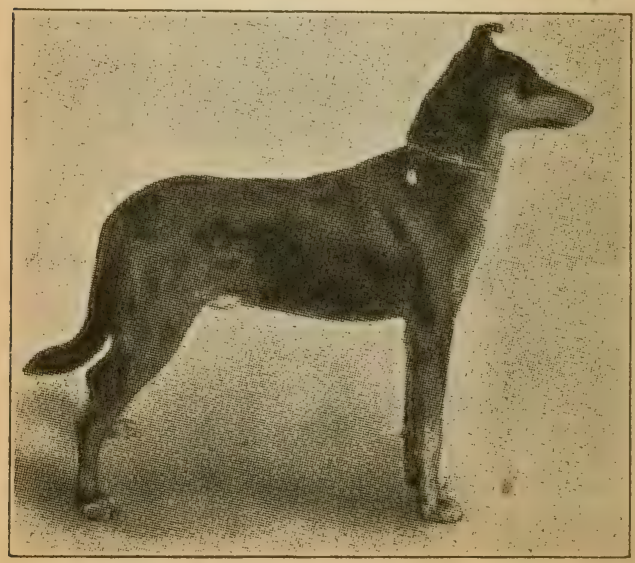

THE SMOOTH.COATED COLLIE FERDINAND DE MONTFORT. 
week to make assurance doubly sure. After she is once entirely out of season she may resume her ordinary habits at least during the first five weeks.

It sometimes happens that a dog may not mate with a bitch even if both are so inclined. In such a contingency, unless the owner of the stud dog is an experienced man, he should call in a qualified veterinarian, for such cases generally call for the use of the dilator. These contingencies, though not common, occur occasionally. Sometimes, especially with maiden bitches, it is necessary to resort to force in making the bitch accept the dog; these unions, as a rule, prove just as fruitful as a voluntary service.

The period of gestation averages sixty-three days, varying some times a day or two both ways. Nine weeks, however, is a safe way to figure the time. It is well, during the first weeks of pregnancy, to give the prospective mother a treatment for worms, not 
that these can be directly inherited by the puppies, but they are a drain on the vitality of the bitch which she may well employ otherwise. There are a number of good and safe vermifuges on the market that will answer the purpose. Personally I prefer Le Roy's, but this is, perhaps, because I am familiar with the ingredients.

The bitch should have regular exercise up to the fifth week and in her natural sphere. If she has been accustomed to hunting or driving cattle, allow her to follow her ordinary pursuits. At five weeks, if she is in whelp a slight change will be noticeable in her appearance. At six, one is enabled to tell almost to a certainty in most bitches, though not all. After the fifth week, if she shows signs of being in whelp, she should only be allowed moderate exercise, and if she is an old matron which might at any time be given to aborting, she must be kept somewhere, in a kennel or yard, where she cannot jump either 


\section{The Farmer's Dog}

over the fence or on high benches or stands.

The whelping place should be in some dark corner of the barn away from other dogs or sights and sounds. Generally, if a bitch is allowed her freedom she will select her own whelping place, and she usually has this picked out long before her time, and no matter how attractive artificial surroundings may be made for her, she will go to the place of her own selection, and this will generally be under the barn or outbuilding, or under a manger. In summer I believe in giving the bitch as much leeway as possible, for I am a great believer in the nature method. I have had dogs in the country on many different occasions, where puppies that afterward proved to be winners were raised under old stalls or buildings, and which proved to be hardier than any that I ever saw or raised under strictly artificial surroundings. In winter, of course, it would be impossible to allow the mother too much 
latitude, for newly-born puppies cannot thrive in a temperature much under sixty-five degrees. As a matter of fact, the whelping room should be about seventy degrees Fahrenheit in winter, hence if no regular artificially heated kennel is provided, the prospective mother should be brought into a room in the house or basement that can be heated. If a whelping place is provided, this should be only a platform raised an inch or two from the ground over which a carpet may be tacked. This covering should be removed after the puppies are born, and straw may then be substituted. During the hours of parturition, the mother will do much better if she is left alone. Occasionally there may be complications, but in the breeds in which we are at present interested, this is very rare. To look in occasionally, pat her on the head, or offer her a drink of water is only humane, and will be appreciated, but officious interference only invites disaster. If the weather is very cold the puppies 


\section{The Farmer's Dog}

may be taken away as they are born and placed in a basket by the stove, wrapping them first in a warm blanket, but as far as first aid to the puppies is concerned, that will be taken care of entirely by the mother. The best advice is, leave her alone and let nature take its course, unless complications actually set in. The mother instinct is so strong in the female of the canine species, that she knows better what to do than all the artificial aid the human mind can devise. 


\section{CHAPTER III.}

Care After Whelping-Care of the Pup. pies During First Fere Weeks-Docking Tails-Vermifuges-Weaning.

UNLESS the mother has gone away and found her own whelping place under some barn or manger, you have, no doubt, kept watch over her and are therefore aware when the hours of labor are over. It is well to sponge her off with luke warm water, but dry her thoroughly. Remove the carpet which was in the whelping box. You may either tack another on the floor of this or leave it bare with the exception of the clean straw which, it is assumed, you have provided. Offer the mother some food and water after her strenuous period.

The food may consist of milk, broth or gruel. As a matter of fact, for the first three days sloppy foods of this nature are preferable, although this 


\section{The Farmer's Dog}

does not have to be continued. After the third day allow her her meat as usual, and see that she is fed three times daily. She has other mouths dependent upon her now and her vitality must be sustained. If the season of the year is summer, it is likely that she will be infested with a certain amount of fleas, no matter how one tries to keep the surroundings clean. After the first few days the mother may be dipped in any of the solutions made for the purpose, but the puppies, which are just as likely to be infested cannot be treated in this manner. After they are a week old, however, it is safe to dust them with Persian insect powder. See that none of this enters their mouths or eyes, however, and after it is well brushed into the coat, be as careful to brush it out again. The puppies may be placed over a paper while this process is being gone through. Afterward, paper, powder, fleas and all may be burned. In warm weather the puppies should be treated thus at 
least once a week, especially if they are living in a place which is likely to be infested with a greater abundance of fleas than ordinary. During all those early weeks, the mother will look after the puppies herself, keeping the sleeping box clean and performing the ablutions upon the puppies, so nothing need be done to them, except, if they happen to be Airedales, then then they must have their tails docked before their eyes open, which is about the ninth day. The process is a simple one; take the puppy in one hand, push back the skin on the tail toward the body, and with a sharp shears, held in the other hand, snip off about one-third or two-fifths, according to the dictates of fashion. At the present time it is the mode for Airedales to have rather longer caudal appendages than was formerly the case, some even preferring to dock them to about one-half inch. There is no need to apply anything to the wound; the bleeding is very slight, and in a few days, through the minis- 


\section{The Farmer's Dog}

trations of the mother, the tails will heal rapidly, for by drawing the skin back when the operation is performed, this soon grows together and not the slightest trace of a scar is noticeable.

- Internal parasites - that is worms -will be found in all puppies even as young as two or three weeks, for no matter how thoroughly the mother has been treated, nor how calm she may be, the ova are about somewhere and the puppies are sure to absorb them.

I have safely given Le Roy's in liquid form at two and three weeks of age, by floating a little of the medicine on a half teaspoon of the dam's milk and the results have always been eminently satisfactory. Another good vermifuge for puppies is the fluid extract of pink and senna in doses of five to thirty drops, according to the age and the breed. In giving any vermifuge, however, it is always safe to take the minimum dose as a 
guide and rather give too little than too much.

About the third week it is safe to teach the puppies to lap milk. Although the dam's milk is richer than that of the cow, most breeders find it more satisfactory to begin by diluting cow's milk one-half with luke-warm dater. Place this in a shallow pan, bring the puppies up to this and dip their noses into it. They will soon learn to lap it of their own accord and then when the time comes for weaning, which ordinarily should take place about the seventh or eighth week, there will be slight trouble. As long as the bitch is well and strong there is no need to wean the puppies too young unless the mother shows a disposition to desert them. In the early days milk is the staple diet, but they may soon be given this poured over stale, broken up bread or any of the puppy meals that are on the market. A little raw or cooked meat chopped up finely, may also be given three or four times a week with 
very good results. Do not pay any attention to the old misconception that meat is injurious to puppies; it is not. This is the natural diet of the canine and is the most nourishing food in the highest form of concentration that can be given. I have given meat, both raw and cooked, to puppies at seven and eight weeks old and fed others of the same age milk and breadstuffs only, and found that those which were fed the meat grew faster, were more vigorous and healthy and had a more prosperous appearance in general than the milkfed puppies. The idea of feeding concentrated foods is to avoid overloading the stomach, and in this connection it might be said that from the time they are weaned the puppies should be fed about once every four hours up until late into the night, and the first feed in the morning should be given at daylight. As the puppies grow older they may be fed less frequently and in larger quantities. Care should always be taken that 
80

\section{The Farmer's Dog}

they have access to an abundance of fresh water at all times, which should be placed in earthenware vessels if possible. The food vessels should be scalded after each meal to prevent the possibility of any left-over sour food from contaminating the next meal, for this is a frequent source of bowel trouble in puppies, and much of this can be prevented if ordinary care is taken. 


\section{CHAPTER IV.}

Selection of Puppies-Value of Bitches to Preserve Strain-How to Market -Conditions of Sale-How to Ship.

$7 \mathrm{HE}$ wise breeder will dispose of 1 his surplus puppies at an age that is as early as is compatible with the future welfare of the rapidlygrowing youngsters. This age is approximately between eight and twelve weeks. Some breeders dispose of their puppies as early as six or seven weeks, but this is not advisable, for they are not yet able to take care of themselves so early in life and more are apt to go wrong. At eight weeks, however, it is time to begin to think of selecting those that are to be kept for future use and to find proper homes for the others.

The question of selecting puppies is not such a difficult one as one might imagine. Most breeders prefer to keep a bitch or two out of a promis- 
ing litter of well-bred puppies, in order to retain the blood in the kennel. The principal thing that one is guided by at this early age is correct markings and the general disposition of the youngster. The keynote of success is to select the boldest and wisest ones, that are correctly marked, for even at the early age of eight weeks it will be clearly noticeable that one or more in the litter are just a trifle more precocious than the others. After the selection has been made, then the others should be graded according to their qualifications and a price put on them according to their merits. For instance, the first choice dog puppy should bring more than the second choice and the first choice bitch puppy should command a higher price than the second or third choice, and so on. In breeds where markings play an important part, this must necessarily be the principal desideratum. As a matter of fact, this applies particularly to Airedales, collies and shepherd dogs. In pointers, 
setters and beagles it is not so important. Airedales with the black saddle and deep tan markings command more money than the lightcolored ones and a correctly marked collie is also more in demand. If there are off-marked ones, they may be priced accordingly, but in making out a descriptive list care should be taken that each and every puppy should be described just as he is. The markings must be given precisely, and if the puppy has any faults or peculiarities, these must be elucidated. No breeder starting out to sell dogs in the open market will thrive long if he resorts to misrepresentation.

The sale should invariably be a cash transaction, but the puppy must be sold with the guarantee that he is exactly as represented and in the best of health. Any deviation from this rule is disastrous. It should also be understood that in the event the purchaser is not pleased he may return the puppy and get his money back. 
There may be times when it is necessary to refund the purchase price of a puppy when there are no real grounds for it, but in the final analysis, this is more profitable than to make a dissatisfied customer. Pleased customers will soon be the best advertisers, but one dissatisfied patron will do more harm than many times the price of the puppy. Years ago I bred pointers on a rather large scale, and by following this rule there was seldom any trouble. I recall one instance where a patron received his puppy, but was dissatisfied with his markings. I immediately wired him to return the puppy at my expense. In the meantime, however, I received a telegram from an unknown person who had seen the puppy in the express office. The youngster evidently pleased this man for he offered to take the puppy out of the express office at the price named. The result was, the first customer was perfectly satisfied with the transaction and ordered another puppy which pleased him, 


\section{The Farmer's Dog}

85

while the first puppy was the means of making another customer. It happened that this puppy which was refused by the first man turned out to be a frequent bench winner and one of the best shooting dogs in that part of the state, and thus was the means of more good advertising than if the demands of the first patron had been ignored.

The question of marketing puppies is not a difficult one at this present day and date, for there is an unusual demand for well-bred dogs of all varieties. There is always more or less local demand for good puppies, but as a rule, such as are sold near at home seldom bring the prices that one is enabled to obtain by offering them to dog lovers at large. The only way to do this is to advertise in papers and magazines that reach such people. The media of the first class are the kennel publications, either weekly or monthly. These appeal to those who know dogs and if you have the right kind of stock to sell, much of the 
86

The Farmer's Dog

business will be done with very little correspondence. But again I must impress upon the beginner, that under no conditions must he misrepresent the stock that he is offering for sale. The next class of publication is the monthly or weekly out-door magazine. Nearly all readers of such publications are dog lovers and dog buyers, and will pay a good price for stock that is hight grade, furthermore, such publications have a wide appeal, going to all parts of the United States and even to foreign countries. Thirty years ago, when I was breeding pointers I sold a pair of young dogs to Japan and the sale was made through a small ad. which appeared in a weekly paper devoted to dogs and outdoor sports in general. Manifestly, much depends upon the variety of dog that one has to sell as to class of advertising medium. If one is interested in sporting dogs, then he must oppeal to that body of sportsmen through the papers or magazines they read, and these are any of the weekly 
or monthly out-door publications. If he is catering more specifically to the farmer, then the various rural publications will bring results, but at the same time it must not be forgotten that those publications which maintain a regular kennel department always reach a class of good buyers, and no matter how restricted one makes his advertising appropriation, he should never fail to use at least one of these, if not at all times, at least quite frequently. The prices that are paid nowadays for high-class dogs justifies maintaining a standing appropriation for advertising in as many publications as one can conveniently maintain, all dependent, of course, upon how many puppies one is likely to have for sale each year.

Puppies should be shipped in light wooden or wire crates, either made especially for the purpose, or out of store boxes, but if one ships many puppies it will pay to have small boxes or crates made, though, as I have said, this is not absolutely es- 
88

\section{The Farmer's Dog}

sential, as long as the receptacle is large enough for the puppy to stand up and turn around in. In one corner, a vessel should be attached to the side, and on the top of the crate instructions should be written so the expressmen enroute may water and feed. Usually they do this, but it is well to have these instructions labeled upon the box in a conspicuous place. If the distance is short-say twentyfour hours-it is not necessary to feed enroute, but if shipments are made across the continent, as they frequently are, then it is imperative. Start the puppy out with a large bone in the crate for him to gnaw upon and amuse himself, but it is well to attach to the crate a small bag of dog cakes which the agents along the route may feed to the youngster while on his long journey. It is surprising how well a puppy as young as three or four months will stand these long journeys. Usually they come through none the worse for their experience. In all my transactions I never 


\section{The Farmer's Dog 89}

shipped a puppy that did not arrive safely at its destination, although I have frequently heard of cases of grown dogs which were smothered in their crates on very short trips, but this was invariably traced to the carelessness of express agents along the route. 



\section{PART THREE}

\section{Training for Practical Purposes}





\section{CHAPTER I.}

Early Training Lessons for All Breeds.

WE are all agreed that the education of a child cannot begin with the higher sciences. He must go through the various preliminary grades before he is ready for high school and it is only after the prescribed course here that he is enabled to enter college. Just so with the puppy. No intelligent owner will expect his three or four months old dog to take to the work of driving cattle, or guarding the flocks or hunting for game until he grows up and has had his training in the calling for which he is intended.

The farmer dog-lover will obtain the most out of his dogs if he has the grown-up ones trained for some special purpose, which, naturally depends upon what breed of dog he is interested in. If it is a collie, a shepherd dog or any of the pastoral va- 
rieties, he will want to make him subservient to his own uses in the care of the live stock. If he is a pointer or a setter, he naturally wishes him to be proficient in the calling of hunting for birds; if he is a hound of some variety, he should be schooled along his special lines, or if an Airedale, the possibilities are that his owner may be able to train him for a generally all-round useful dog which will fit in anywhere. Any person who has a love for the dog will be able to train his own, provided he knows the fundamentals, possesses an even temper and is not inclined to be impetuous, for it takes time and patience to properly train a dog. Some men can do so after reading a book on training and do it perfectly. Others would never be able to perfect a dog in any line of endeavor, even though he read every book that was ever written on dog training.

The early lessons of a puppy are practically the same, no matter what the breed, and these lessons may be 
started as soon as the youngster is out of his nest. The first thing he must learn is obedience and the preliminary lesson is teaching him his name.

The confiding nature of all young puppies is such that they will generally come voluntarily when their attention is attracted. It is only older dogs, which have learned the hard knocks of the world, that will slink away from those they mistrust. Call the puppy to you and use the name frequently while doing so, when he comes close enough offer him a bit to eat, either a cracker or a small piece of meat. Do this frequently at odd intervals during the day and in a few days he will learn to associate the sound of the name with the morsel of choice food, hence to come will be a pleasure. Never, under any circumstances, use force or harshness with a puppy so young. As he grows older, be firm, enforce every command, but severity need never be practiced.

After this first lesson has been 
taught he may next be made to "charge" or drop when told to do so. Any word of command may be used for this, such as "charge!" "drop!" "down!" etc. Whatever form is used, however, should invariably be adhered to. The puppy should not be commanded to drop on one occasion and to charge at another. The idea is for him to associate a word of command with what he is intended to do when he hears that word. Call the puppy to you, and put him down on the ground or floor in the position you wish him to assume. Hold him in this position several minutes and keep repeating the word of command during the process. Naturally, as soon as you release him he will be up, but again reward him with something to eat. Repeat several times, but do not tire the puppy by making the lessons too long. Gradually, as lesson follows lesson, you may remove the hands from the puppy, but if he attempts to get up, force him down and repeat the command. Hold him a 


\section{The Farmer's Dog}

moment, keep repeating the word, remove the hands again, but continue to repeat the command and force him in position every time he attempts to rise. When you want him to rise, give the command, "up!" After the lesson reward again. The puppy will soon learn what you expect of him and it will dawn upon him that after lying in this position for a time he will not only be pleasing his master, but will be rewarded also. Do not hurry, do not frighten the puppy, do not be severe, but be calmly firm in every lesson that is given.

During this period the puppy may also be broken to retrieve by the "play method" as described in my previous book "The Working Dog and His Education." That is, of course, if you wish to make a retriever of him and it may be said in passing that this is a very convenient accomplishment for a dog to possess. The lessons are entertaining for a puppy, for there are few which will not run after and retrieve a ball when thrown out. The 
98

\section{The Farmer's Dog}

idea that must be impressed upon the pupil is that it is all play, but at the same time, he must not be allowed to run away with the ball, but bring it to you, and if his first lesson of coming when called has been thoroughly taught, the others usually dove-tail in very well.

House breaking should also be part of the early curriculum of all dogs. This may be done by a little careful watching. Catch him in the act and banish him from the house. This, repeated a few times will teach him to understand, for most dogs are cleanly in their habits. If they still persist after being put out a dozen or more times, reprimand them and keep them banished from the house for a time. As they grow older it is well to establish a custom of putting them out at regular intervals. They will soon learn to regulate their habits according to these periods out of doors.

If the dog you are training is one of the sporting varieties, he should be hunted all during this early period 


\section{The Farmer's Dog}

according to his inclinations, provided, of course, the season of the year is right. Allow them to get out in the woods and fields, to hunt and chase to their heart's content. If the puppy is one of the pastoral variety, let him follow you to the barn or the pasture where the sheep, or swine, or cattle are. In other words, let the puppy become acquainted with the things he will encounter in afterlife, at as early a period as possible. We are assuming that the puppy obeys promptly by this time and will come to your call. It is well now to teach him to come to the whistle. There are times when the dog may get so far away, that he cannot be called or directed by the voice. The whistle may be used on all occasions; either the ordinary dog whistle or some prefer using the mouth, but use the same style of blast on every occasion. Turn the puppy out and allow him to go a considerable distance from you, then blow your whistle and call immediately after. A motion of 
the arm may also be used in this connection, thus in teaching him the whistle you may also teach him to come in or go out by motion of the hand or arm. Be careful to use the same motions every time, however. Practice this every day and the puppy will soon learn to understand that one long blast means come in and if you care to use it, two short ones means to continue to go. The motion of the arms is to indicate the direction.

Remaining at heel is another accomplishment every dog should know and considering how easily this is taught, there is no reason why your dog should be at everybody's feet or all over them, much to some people's disgust, for it must be borne in mind that there are a number of "cranks" in this world who despise dogs on general principles, if for no other cause. First, however, the puppy must be taught to lead. This may be done in a day or two. The puppy when he feels the restraint of the col- 


\section{The Farmer's Dog 101}

lar about his neck may object and pull backward, but coax him to you, give him a bite to eat, pet him-and then draw him along farther. He will soon learn that he has nothing to fear from the lead and will soon trot along nicely or tug at the lead unless you teach him to remain at heel. In order to accomplish this begin by taking the dog out on lead, when he runs ahead of you give the lead a tug, bringing him back of you and as you do so give the command, "Heel!" Repeat this every day for several days or a week if necessary, then start out without the lead on his neck and keep the dog back of you. In place of the lead, carry a small and light switch; if he attempts to pass you, tap him lightly on the nose, commanding him to "Heel!" He may dart past you a few times, but invariably call him back to heel and if he persists in leaving his place, put the lead back on him until he learns that it is absolutely necessary to remain back of you until you give the order to "Hie on!" The 
lesson may take more time than some of the others, but persistence and a quiet, but firm demeanor will soon inculcate the lesson into the pupil's mind so that he will not forget, and even though you traverse the streets of the busiest city, your dog will behave properly at all times. Toy dogs and small terriers will, of course, not be susceptible to this kind of training, but I have seen Airedales so well trained in this respect that they would put many a supposedly perfectly broken bird dog to shame in obeying commands, and obeying them cheerfully.

There are times when dogs need punishment, but this does not mean the severe abuse that some impetuous, high-tempered people are prone to administer in moments of anger. The whip is all right in the hands of some; in others it is an implement of torture, and the man who cannot use it with discretion should either not attempt to train dogs, or he should do so without this form of chastisement. 


\section{The Farmer's Dog}

It is scarcely necessary to say that before the puppy is six months of age he should receive no corporeal punishment and any offenses that he may commit in his early puppy days should be corrected with a reprimand, which he will soon learn to understand. It is quite likely, therefore, that by the time he is six months of age, he may not need the whip and if so, very seldom. To chastise a puppy or an older dog, for that matter, very severely, is taking a long chance, for a dog's spirit, especially a highly bred one - may easily be broken and that being the case, you have a sour dispositioned dog, who does your bidding because he fears punishment and not because he enjoys doing so for the love of his master. It may be well to impress upon the novice that all commands should be given in a low, firm voice and the words for each should always be the same. Loud talking or yelling, especially if a different form of expression is used on each occasion, only 


\section{The Farmer's Dog}

confuses the dog and nothing is gained. If it is necessary to use the whip, always be sure that the dog knows what he is being punished for. It is useless to punish a dog unless you catch him in the act for which you punish him. By all means remember that one must keep his temper and a few judicious blows given in a cool manner, repeating the while the command which you wish the dog to learn, will do more good than an unmerciful beating by one whose temper has gotten beyond his control. The teacher is as much in need of training as the pupil under such circumstances. Assuming that punishment has been administered in the proper manner, do not immediately counteract it by petting the puppy and "make over him." Let him reason it out for himself by remaining quiet and paying no attention to him. The chances are, he will soon come crawling up as if asking for sympathy. Pat him on the head, give him a kind word or two and go on with 
the training. He will no doubt go about his work as cheerfully as before, but retain a distinct remembrance of the chastisement which he will associate with the fact that he has been caught in the commission of the fault and not lose any of his confidence and affection. Do not forget that dogs are like human beings and like to be praised for their good work. Therefore, when your dog does what you ask him to do, always reward him with a few kind words, and during the early stages of his lessons, invariably give him a choice tid-bit as an additional incentive to do what is asked of him. By this, however, it is not meant that a dog should be praised or spoken to while he is performing what you command him to do, allow him to complete what he has set out to do. Too much talking will confuse the pupil. Hold all praise in abeyance until the trick you expect him to perform is perfectly accomplished.

With these fundamentals, the ama- 


\section{6 \\ The Farmer's Dog}

teur dog-lover may proceed with any breed. As a matter of fact, when it comes to hunting dogs, such as pointers, setters, beagles, fox hounds, or Airedales, he will have the foundations for a practical education laid and all that will be necessary is to proceed in the field in a judicious way, whatever the lie of work may be to which the dog is to be accustomed. An abundance of practice in that particular sphere is the surest way to perfect the dog; go slowly, do not crowd, but be persevering and if some knotty questions arise that ordinary logic may not solve, the ambitious amateur is referred to my book on training, "The Working Dog and His Education." 


\section{CHAPTER II.}

The Training of the Stock Dog-For General Use on the Farm.

IN the previous chapter I dwelt upon 1 the preliminary training that should be taught all breeds whether they are to be used for hunting or for stock work, for though some may differ in this opinion, I believe the dog which has been taught to heed the ordinary commands that all of them must eventually come to obey, is more likely and more easily led along the paths of higher education than a perfectly green one. Numerous books are devoted to the training of the bird dog and rabbit hound, but I know of no recent work that treats on the subject of dog training for farm work. This chapter is therefore intended to give some information, crude though it may be, on how to turn such dogs as collies, shepherds and even Airedales, to good use 
in the aid of the stock raiser. In passing, it may be said that there is always a great demand for intelligent farm dogs of this class and the shrewd agriculturalist who takes up the breeding of dogs as a by-product to his farm, may make the industry a most lucrative one by not only selling puppies, but also by breaking a few stock dogs each year, for these command good prices at all times; fully as much so as well broken point-ers, setters, beagles or sporting Airedales.

When the last word is said, the well-trained stock dogs must understand only a few commands, but he must obey unhesitatingly, and here again it is pointed out how useful the preliminary education is. Some dogs are more easily trained than others; some will learn quickly, some will never learn, but by the time you have given a dog his yard lessons you will know his disposition, his temper and his degree of intelligence, therefore it is assumed that when you 


\section{The Farmer's Dog}

begin the practical lessons with your pupil, you understand him fairly well, consequently know how to proceed, and in this connection it might be observed that better results will be obtained if every pupil is handled as an individual. Measures that might be successful for one, might be ruination to another, but knowing the animal well, half the battle is fought.

The time to introduce him to practical work among stock varies much according to the individual. Generally from seven to twelve months, but it is assumed that before the puppy is introduced to the actual work among stock he has been taught to come in at command. If there are any slight traces of a disposition to become heedless he must be given a few force lessons; that is, attach a long lead of about twenty yards to his collar and let him go as he pleases, then call him in; if he refuses, draw him up and call or whistle him in; a few of these experiences will tend to make him remember the commands 
of his earlier days and that when he is called to come in, it means all of that.

If it is among sheep that you are working him he should be taught to drive them to one particular point for a week. Giving the command "Hie on!" and the motion of the arm signifying the direction. Young dogs are apt to be impetuous and may be inclined to rush the sheep. Should this occur, restrain them, even if it is necessary to apply the check cord. Other dogs may not drive at all, but remain by your side. Nevertheless, such a dog will follow and become deeply interested in what you are doing. Gradually he will assist in the driving without appearing to do so. Continue to use the hand and arm signais as indicated in the preliminary lessons. In windy weather the dog will see the signals when he could not hear your voice or the sound of the whistle. If perchance, the stock is on a wide plain and scattered, the dog may be so far away that he may 


\section{The Farmer's Dog 111}

not even see the motion of the arm. It is well, therefore, as an aid in catching the signals, to use a red or white handkerchief in giving them. Red can be seen long distances and is distinctive. The motion in either direction will soon be understood. $\mathrm{He}$ must also be taught that the handkerchief held straight up means to stop, or "that will do." This should be done by the aid of the whistle to attract his attention; as he acquires more experience he will come to watch for these signals without the whistle, and it is then that distance will not make much difference, for whether he hears or not, he will understand the signal. As before stated, if he is too impetuous, work him with the cord and use the word "steady!" and if he fails to heed, give the cord a sharp jerk, repeating the command. The puppy should not be given too much work until he has the strength. and speed to circle the flock. If he lacks in these qualities he will run straight and frighten the sheep, 
whereas he should be taught by the motions of the arm to circle them and come in front in order to turn them. Collies of the working types usually take to this work very readily, while Airedales are inclined to be too headlong at first, hence the check cord must always be ready for use. Once they become accustomed to the work, however, and understand your commands, they will work as well as any of the shepherd varieties. Always remember, however, that the rashness of the ebullient young dog must be regulated, not by whipping, but by the use of the collar and check cord, and words of reprimand. This is but the natural excess of zeal that any healthy young dog of promising qualities displays. When he has learned fully to obey the command "Steady!" there will be little further trouble with him, but until he has learned these commands, extreme caution and patience are essential. If it is feasible to take a small flock on 


\section{The Farmer's Dog 113}

a fenced road or lane progress will be made even much more rapidly.

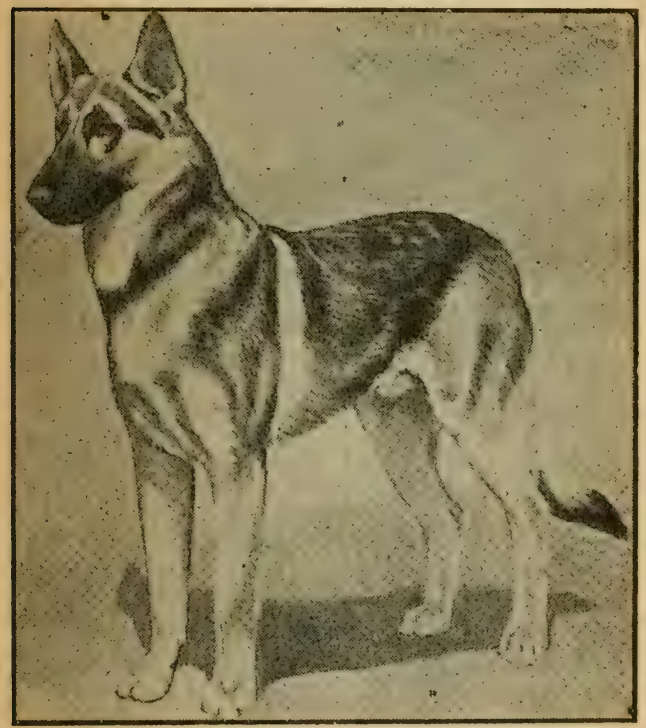

THE SHEPHERD DOG, BUDDY OF SWIFT RUN,

The next step is to teach the pupil to "speak" to the sheep if you wish to have them hurried along. This could have been taught him in his 
yard training lessons, by holding some bit to eat just out of his reach and commanding him to "Speak!" All puppies will soon learn this, then when it comes to the practical work all that is necessary is to give the coinmand to "Speak!" at the same time urging him to "Hie on!" in the direction you wish him to go-that is, toward the sheep-to urge them to greater speed in crossing a creek or railroad. After the dangerous crossing is passed you do not wish to have him continue barking, in which event give the command "quiet!" making a motion toward him until he learns that when he hears the word "quiet" he must desist. These terms, "quiet" and "steady," are very convenient after the dog is once broken, if at times he should become too turbulent with his charges and crowd them too much. After a little practice it will be easy to send the dog from one side of the flock to the other. To do this he should then be taught to pass up along the side of the flock. This is 


\section{The Farmer's Dog}

also done by a motion of the arm, indicating the direction, or if he does not understand, give him a start by throwing a stick or other object where he is expected to go, and giving the command, "Up!", "Forward!" or any other suitable word, repeating the motion of the hand until he understands. This, naturally, will take some practice and the trainer must not lose patience. The dog may go only part of the way, or he may not understand, but the motion must be repeated and also the command, and sometimes it is necessary for the trainer to go part of the way, motioning and giving the command until the dog goes the full length on one side of the flock. By degrees he will reach the head of the flock and perhaps go partly around it. The trainer should then quickly change his position, going to the left side of the sheep. If the dog is not too far off he will notice the change in the trainer's position and it is more than probable that he will pass entirely around the 


\section{The Farmer's Dog}

head of the flock, when he should be attracted by voice or whistle and ordered to come in, thus he will come down along the left side after having entirely circled the flock. Should he go through this without error, praise and pet him and give him the same lesson when the opportunity offers. He will no doubt perform better the next time. A reward of a bit of meat is not out of place here; as a matter of fact, the less punishment and the more rewards the dog receives, the more likely he is to perform his duties with alacrity.

It requires a great amount of patience to bring the dog to this kind of work, but perseverance will win out, provided you do not expect your dog to learn too much at one time. An experienced collie, one which has been thoroughly trained, will sometimes run over the backs of the sheep when they are bunched, in order to head them when the occasion demands, but do not expect these fancy feats from your puppy all at once. 


\section{The Farmer's Dog}

If he acquires it in time all well and good, if not, be content that he shows the speed and the intelligence to round them by going to the head and around the flock.

After the pupil has mastered the lesson of passing up and around the flock, the next step is to teach him to herd them, in order to keep them from straying, or for the purpose of driving them from one point to another. This is accomplished by calling the dog up near you and giving a circling motion from left to right and right to left, giving the command, "Around them!" Possibly one or more have strayed farther from the flock; such should be pointed out in order to have the dog make his circle wide enough to include the stragglers. In rounding up these, point them out and when the dog reaches them give the command, "Back!" and motion in the direction of the flock. It may be necessary for the trainer to go to the head of the flock himself and urge him on by the term he learned in 
circling, but not under any circumstances should the terms be alternated or confused, and furthermore the trainer must not become excited himself. Keep giving the command "Back!" until he understands what is meant. If the dog is ordinarily intelligent, he will soon learn that this word means that the sheep must be gotten together in a closely-bunched flock.

The dog should also be taught his place and to remain there when not in action either in the rear or the front of the flock. If he has been taught to drop in his preliminary yard lessons, this will be easy, for all that is necessary is to drop him where you wish to have him stay. A few reprimands, should he attempt to leave the place before told to do so, will be sufficient to recall his early lessons. It is advisable to give him an article of clothing to watch while he is thus dropped and it is surprising how the average collie, or shepherd, or Airedale will understand'this and 
strictly guard the master's belong ings.

Occasionally the occasion arises when sheep must be driven through fenced lanes where, in order to send the dog to the head of the flock it is necessary to have him jump the fence. This can be taught by calling him to the fence and motioning him over with the words "Hie over!" then give the regular commands to send him to the head of the flock. If the dog is slow in learning to jump a fence, he must be helped or forced over while the command is being given by word and signal.

Sometimes sheep are driven on roads along which the fences have many gaps through which the sheep might slip away, or there may be cross-roads down which they are prone to turn. When such an opening is encountered the best thing to do is to send the dog to this place and drop him, ordering him to "Hold them!" If a straggler should slip through in spite of this, the dog is ordered after 
him with the command "Back!" As a rule, however, the dog soon learns to keep the sheep in line if he is stationed at a gap or cross-road. If the dog has mastered these lessons he is well on the way toward making a good sheep-herder's assistant, but he is not yet an entirely finished dog. 


\section{CHAPTER III.}

Training of the Stock Dog-Continued.

$\mathrm{A} S$ the trainer comes to that stage $A$ in the dog's education when he wishes to teach him to hold the sheep in front, it may be necessary to have an assistant to drive them while he goes on to the front with the dog, but failing in obtaining an assistant this may be accomplished by driving the sheep to a narrow pass. Once started, they will attempt to go through this. Here the trainer goes to the front with his dog, stops him in front of the sheep and commands, "Hold front!" extending the arms as if barring the way. The dog will watch you with interest and go into it with a vim, for dogs are imitators, and if the trainer performs his part properly the pupil will soon follow the example that is set. After he becomes experienced in this, it is only a short step to the next lesson, which 
is sending him to the head of the flock to "hold front," by extending the arm and pointing in that direction. After he reaches the proper place he is easily directed by swinging the arms to the right and left and repeating the command. When you wish to have him desist, hold one arm straight up and cry, "That will do!"

The term, "Hold!" will be found very useful at crossings where others have the right of way. It is especially necessary on the prairies when another flock is crossing in front of the trainer's flock at right angles. It should be borne in mind that a flock with lambs always holds the right of way; this is an established usage. When the pupil has advanced thus far it is an easy matter to teach the finer points to "hold right" or "hold left." Only experience will teach him this, but the motion of the arms will indicate what is meant by right and left. When you want him in to do the driving, call or whistle him to you, commanding him to "Heel!" until 
you have him in hand, then give the command to "Hie on!" and allow him to do the driving. It may be necessary for the trainer to go in front of the flock and leave the dog behind to continue the driving; should he attempt to follow, wave him back with the word "Heel!" and continue on, always being prepared, however, to send him back should he leave his place. Encourage him to drive by giving the command "Hie on!" and should some of the sheep attempt to lag, the trainer should encourage him with the word "Speak!" This will animate the dog and cause him to become more interested in his own work. By practicing this for some time, always going a little farther up alongside of the flock each time, the trainer will soon have his dog so perfect that even though he should go out of sight, the dog will continue driving.

Whenever sheep take to a fence corner, or dry ditch, or water course, or seek refuge behind an obstruction of any kind, and refuse to move, send 


\section{The Farmer's Dog}

the dog "Over" and "Around" them in such manner that he comes directly behind the unruly ones. This will generally start them in the right direction.

The next step is to "fetch" the flock to you or "fetch" them home. To instruct him in this quickly and thoroughly, take him to the pasture with you and give the command "Fetch them!" waving the arm in the direction of the sheep and starting toward them, if the pupil does not understand. While walking in the direction of the flock, continue repeating the command, "Fetch them." It will not require many lessons for him to understand what is meant by this command and you will soon be enabled to get the dog to start the sheep and turn your back while the pupil does the work. Always be sure to use the same terms for each class of work-which I pointed out earlierfor nothing is so confusing to a dog as to have a command given in several different ways. If this rule is ad- 


\section{The Farmer's Dog}

hered to, in time one can make a perfect dog of any intelligent animal, not only of the strictly shepherd persuasion, but also of yarious other breeds. It is the confusion of orders that do so much damage to the thoroughly trained stock dog, hence, in the event that the animal is placed in charge of another person other than his trainer, care should be taken that the new man understands the proper orders, for frequently it is the man and not the dog that it at fault, if the latter does not do his work well.

The idea that it is necessary to have another thoroughly experienced dog along to teach a youngster is erroneous. While a well-broken, steady dog is of some value, in most cases an illy broken old dog will only disconcert the new one. Take the dog out alone for his lessons, follow the instructions implicitly and the reward will be realized in the thoroughly educated stock dog which all agricultur- 


\section{The Farmer's Dog}

ists who raise stock of any kind consider more valuable than any other possession about the farm.

Dogs may be broken to take cattle and sheep to and from the pasture in the same manner as they are taught to handle sheep. Sometimes an unruly bovine of the male persuasion may be inclined to cause trouble, but the sagacious dog of experience will soon learn how to handle such a contingency. I had an Airedale on one occasion which gave a recalcitrant bull a lesson that he never forgot, when the latter attempted to show his unwillingness to be taken out of a pasture. The dog was Teddy the Terror. He is now an old dog, but in his prime he was one of the best all-round farm dogs imaginable. $\mathrm{He}$ was only another example of what may be done with an intelligent dog if he is handled properly.

I am hoping that all the good dog lovers of the rural districts may be en- 


\section{The Farmer's Dog 127}

abled, through the perusal of this book, to develop another Teddy, whether their Teddy be a collie, a shepherd or an Airedale. 



\section{TWENTIETH CENTURY BIRD DOG}

\section{Training and Kennel Management By Er. M. Shelley}

T. VERY owner and every person interested in bird dogs and hunting dogs should have a copy of this valuable book.

Into this book Mr. Shelley has put the best of his knowledge, gained from years of experience as a successful trainer and handler. It is authoritative and interesting, and it throws many new lights upon the old system of bird dog training.

Containing many fine illustrations, and being handsomely bound in cloth, this is an attractive as well as useful volume that you cannot afford to be without.

Price, Postpaid, $\$ 2.00$

\section{SPORTSMAN'S DIGEST}

BOOK DEPARTMENT

Butler Building Cincinnati, Ohio 


\section{Every Bird Dog Fancier Should Have a Copy of}

\section{The Modern Setter}

\section{By A. F. Hochwalt}

A COMPLETE history of the longA haired bird dog. Nothing has been left unsaid. Chapters on the Llewellin and Laverack setters-chapters on every family that assisted in making bird dog history-interesting anecdotes on field trials and field trial happenings-it is a complete story of the various breeds of setter, from their origin down to the present day. Bench show and field trial dogs compared; Irish and Gordon setters fully dwelt upon.

No book on the bird dog has ever been written or is likely to be written that is as comprehensive as this new work.

Size of book-six by nine; bound in silk cloth and gold lettering. Twenty-six full page illustrations; 239 pages of interesting reading matter.

\section{Price per Copy $\$ 4.00$, Postpaid}

\section{SPORTSMAN'S DIGEST}

BOOK DEPARTMENT

Butler Building Cincinnati, Ohio 
A Splendid Book Every Camper Will Want in His Kit

\section{Camp Cookery}

By Horace Kephart

Author of "Camping and Woodcraft," "The Hunting Rifle," etc.

Illustrated with Pen Drawings of Useful Camp Utensils, Outfits, Etc.

TF you want to fully enjoy your next 1 camping trip, learn the fundamentals of camp cooking from a man who has spent many years in the woods. This instructive, valuable book tells you what provisions are essential; what utensils you really need; how to build and get the best results from camp fires; how to dress and keep game, fish, etc. Three interesting chapters tell you all about the preparation of meat, game, fish and shellfish. The author tells you just how to prepare cured meats, eggs, breadstuffs, cereals, vegetables, soups, beverages and dessert. Nothing has been overlooked.

You'll enjoy your next trip to the woods much more after reading and profiting by the valuable suggestions contained in this book

\section{Pages Clothbound $\$ 1.50$}

\section{SPORTSMAN'S DIGEST}

BOOK DEPARTMENT

Butler Building Cincinnati, Ohio 


\section{Practical Dog-Keeping For the Amateur}

Written so as to be Understood By A. F. Hochwalt the eminent authority and writer

THE author has compiled in this 1 valuable book a mass of facts and information in a clear and concise style that can be understood by every one. He has avoided unfamiliar terms and used only words and phrases of our every-day language.

All phases of dog-keeping are carefully explained-the latest methods in feeding, conditioning and groomingdirections on care in case of sickness - observations on breeding - proper diets, and many other important subjects.

If you own a dog and want to know the latest and best methods of caring for it, THIS BOOK WILL PROVE INVALUABLE.

\section{Illustrations}

Prices : Cloth, $\$ 1.50$; Paper, $\$ 1.00$

\section{SPORTSMAN'S DIGEST}

BOOK DEPARTMENT

Butler Building Cincinnati, Ohio 


\section{The Working Dog and His Education}

By A. F. Hochwalt

RE you training a dog? Is he A responding to your methods? Are you satisfied with the results? Would you like to compare your methods with those of famous trainers? Do you want to learn about their methods?-If you do-

\section{GET THIS BOOK}

Interesting chapters on the training of pointers, setters, foxhounds, beagles, Airedales, spaniels, and police dogs. Various systems are described, the best method of breaking faults and correcting bad habits are explained.

It is the work of an expert, written so that the amateur may understand. Every rule in it has been tried and proven. You can rely on the directions given to always produce results.

\section{Price, $\$ 1.00$}

\section{SPORTSMAN'S DIGEST}

BOOK DEPARTMENT

Butler Building Cincinnati, Ohio 


\section{What Sportsman's Digest Will Do Every Month for YOU}

\section{It Entertains You}

with actual-experience stories of the great outdoors. Some of the most prominent sportsmanwriters of the country are monthly contributors to SPORT'SMAN'S DIGEST.

Among them are such well-known writers as Morris Ackerman, Ben C. Robinson, L. H. Sweet, A. F. Hochwalt, Raymond Thompson, L. E. Eubanks, Robert Page Lincoln and scores of others.

\section{It Offers Valuable Suggestions}

in connection with your hunting, fishing and camping trips and enables you to profit by the experience of sportsmen who have made a study of these health-bringing outings.

\section{It Answers Every Question}

of every kind regarding the Great Outdoors. The Quizz Cabin will enlighten you on those points on which you are not entirely clear. A mint of valuable information will be found each month in this most interesting department.

\section{It Keeps You in Touch with the World of Sports}

even though you are busily engaged in the business of making a living. SPORSTMAN'S DIGEST will quickly make you forget any worldly cares-seated by your fireside or on the front porch, you'll travel all over the country-mentally-after big and little game and the voracious battlers of the mountain streams and lakes.

Twelve Big Illustrated Numbers ALL FOR ONE DOLLAR

\section{SPORTSMAN'S DIGEST}

DESK B, BOOK DEPARTMENT, Butler Building Cincinnati, Ohio 


\section{DOGCRAFT}

By A. F. Hochwalt

Third Edition-Revised and Enlarged

HERE is a book every sportsman 11 will want to have in his library for ready reference-and study. It tells everything you want to know about dogs-290 pages of expert information.

DOGCRAFT is a complete study of the various breeds of dogs; their care and management in health and disease. You will find many interesting chapters on gun dogs, sight hunters, house and watch dogs, pastoral dogs-and you'll find out just how the particular breed you are interested in should be trained and cared for.

If you have one dog or a dozen dogs, you will want a copy of this splendid book

Clothbound, $\$ 2.00 \quad$ Paperbound, $\$ 1.50$

\section{SPORTSMAN'S DIGEST}

BOOK' DEPARTMENT Butler Building Cincinnati, Ohio 


\section{The Modern Pointer}

By A. F. HochWÂLT

THE object of this book is to

1 briefly consider the development of a dog which for many years has been one of the favorites of the sportsman, and which is likely to continue so for all time to come.

This is an interesting story of the short-haired dog and his rapid progress in this country. If you are a lover of the bird dog, you'll want a copy of this book. It is six by nine inches in size, contains 162 pages and 23 full page illustrations. Bound in silk cloth with gold lettering.

Price, $\$ 2.00$ per Copy, Postpaid

\section{SPORTSMAN'S DIGEST}

BOOK DEPARTMENT

Butler Building Cincinnati, Ohio 



LIBRARY OF CONGRESS

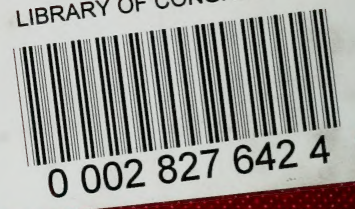

